\title{
UnPlastic My Food: Plastics in Take-Away Packaging, Consumer Behaviors and Eco-Packaging Possibilities
}

\author{
A Master's Thesis by \\ Sara Martí
}

Presented to the department of Design for Social Impact in partial fulfillment of the requirements for "Master of Arts" in Design for Social Impact

\section{PARIS COLLEGE OF ART \\ May 2018}

\author{
Accepted by \\ Linda Jarvin, Dean
}

Klaus Fruchtnis, Associate Dean for Graduate Studies

Alessandro Carabini, Thesis Advisor

Lillian Davies, Master's Thesis Faculty

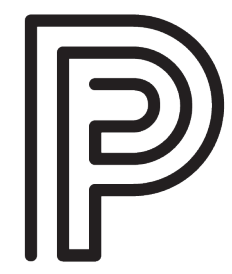


(C) 2018

Sara Martí

ALL RIGHTS RESERVED 


\section{Table of Contents}

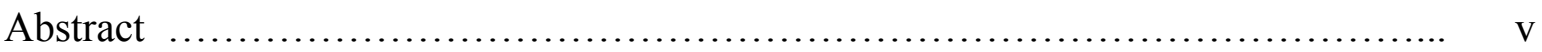

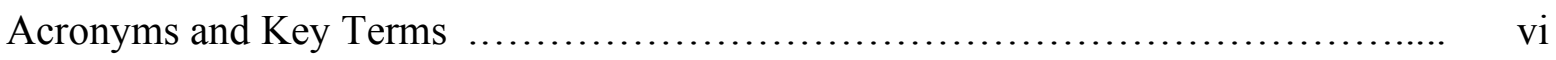

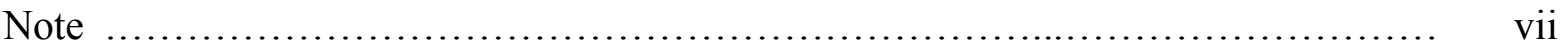

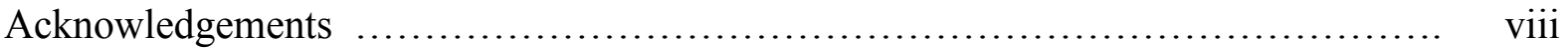

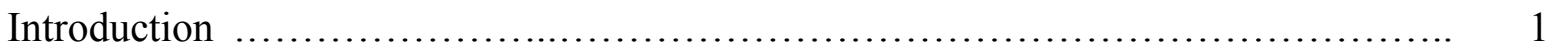

Chapter 1: Understanding Food Packaging and Plastic Food Packaging ............... 2

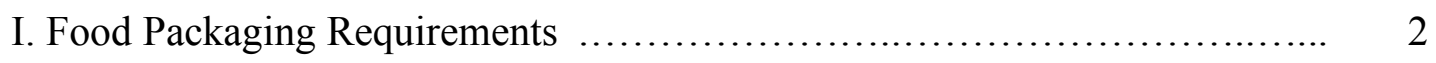

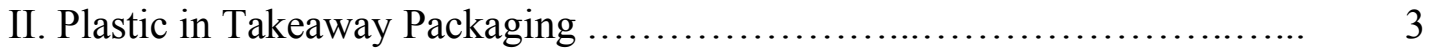

III. Consequences and Responses to Plastic Packaging ........................ 5

Chapter 2: Examining Consumer Behavior and Attitudes ............................ 9

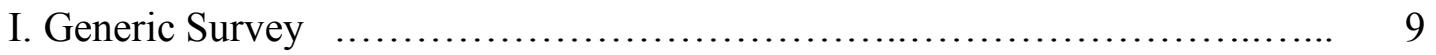

II. Question and Response Analysis ..................................... 9

III. Results Condensed ........................................................ 14

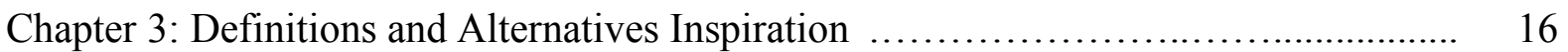

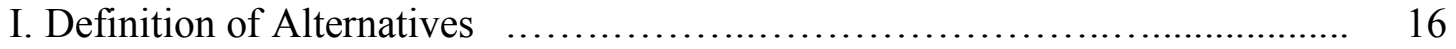

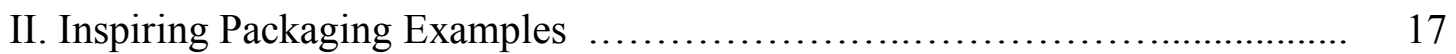

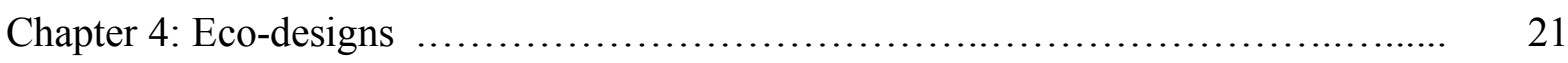

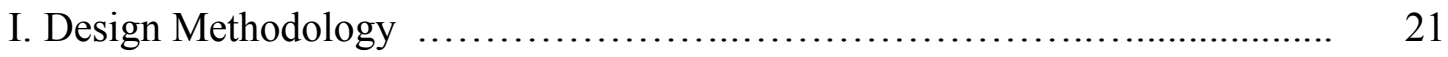

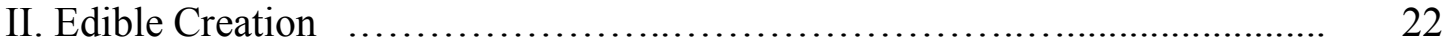

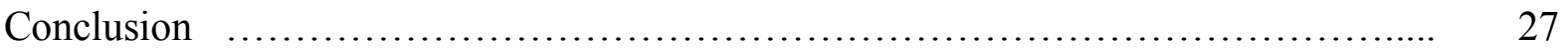

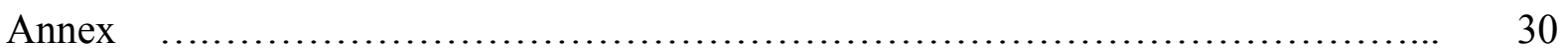

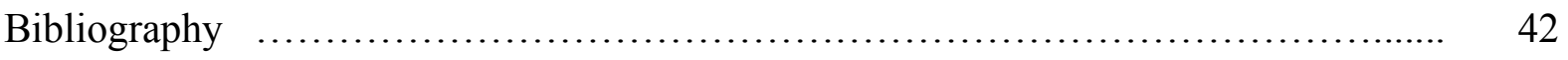




\begin{abstract}
:
Careful design of takeaway food packaging is needed to ensure that it protects, preserves, and contains the contents within. Since WWI, plastic has been used as a material for packaging. However, there is a growing awareness that plastic packaging pollutes environment, kills wildlife, and even poisons human health. As new eco-consciousness trends lean in with plastic concerns, there are increasing efforts to find ecological alternatives to plastic takeaway food packaging. In this thesis, I will examine takeaway food packaging, explain problems and responses to plastic, explore consumer behavior regarding packaging, showcase up-and-coming eco-packaging and finally test my own alternative takeaway food packaging. My goal is to provide an insightful discovery into the current state of packaging design and provide examples to provoke or pivot the consumer conversation towards creative solutions for a more sustainable and healthy future for takeaway food consumers and the planet.
\end{abstract}




\section{Acronyms and Key Terms:}

Takeaway Packaging: the packaging for food that is bought at a restaurant or store and packaged for transportation and consumption at another location.

Plastic: the material created by synthetic chemical construction and used in a variety of objects

Life cycle: the creation, existence and demise of an object

Life cycle analysis: an analysis which attempts to measure the environmental impact of a product throughout its life cycle 
Note:

Plastics includes an extraordinary number of chemical combinations and this wide scale of materials makes "plastic" a categorical umbrella catch-all for a variety of products.

Therefore, for the purpose of this research I will refer to plastics as a descriptive material in Chapter 1 but I will focus on only common food-grade plastic in other further analyses.

\$ This book was printed using 100 percent postconsumer waste paper. 


\section{Acknowledgments:}

I would like to extend my gratitude to my colleagues and peers. To those who let me interview them. To those who indulge me in long talks on trash, plastic and packaging. And to my partner who believes that crazy ideas can sometimes win the day. 


\section{Introduction:}

Takeaway food packaging is like a treasure box. Wrapped, sealed, and packed in a bag - it unwraps like a gift holding delicious meal inside. It sparks anticipation. It elicits desire. It helps to bring a bit of indulgence to the mealtime. That is, until the meal is done, or the food is gone. Then, empty and purposeless, the packaging loses its luster and is quickly discarded. It ends up in the trash.

My grandmother tells me fondly of her younger years when she would pack and take lunch to my grandfather on the farm. Her packaging was simple and reusable with folded handkerchiefs, baskets, and ceramic containers. Her packaging was purposeful. Then, as a child, I gained a whole new appreciation for decorative packaging when my family was stationed in Japan. I remember colorful paper, brilliant folds, even fabric wrapping (called furoshiki). This packaging was special.

Nowadays, takeaway food packaging feels often like an afterthought. A visit to local takeaway shops often results in plastic containers, plastic wrap, plastic pouches and even plastic bags. Clear, printed and squeaky, they lend an air of cheap, easy and guilty all at once. Research has continued to pour in about how plastic could be dangerous for human beings, for wildlife, and for the planet. As an eco-conscious person, I have often wondered if packaging could be made in a way that did not rely on plastic. Could it bring back purpose and joy without causing harm?

In this thesis I attempt to explore takeaway food packaging, plastics in takeaway and eco-alternatives. In my first chapter, I explain the descriptive needs of takeaway packaging, and explain the dilemma of plastic takeaway packaging. Chapter two gives insight on the consumer behaviors and the rising trend for sustainable packaging overall. Chapter three sets the definitions for the sustainable packaging categories and explores up-and-coming alternatives. In chapter four, I showcase my methodology for social impact eco-design in packaging, share several eco-packaging designs and explain the results of workshops I used to test the designs. Finally, in the conclusion section I discuss the results of my thesis and speculate on the future of takeaway packaging in our lives. 


\section{Chapter 1: Understanding Food Packaging and Plastic Food Packaging}

\section{Food Packaging Requirements.}

Packaging is defined by Merriam Webster as simply "material used to enclose or contain something." However, food packaging serves beyond this initial description to also protect, preserve, contain, promote, inform, store, and carry (Marsh \& Bugusu, 2007). As materials have advanced from leaves, shells, hollowed logs (Hook \& Bond, n.d.) to fabric, ceramic, glass, metal and plastic, packaging has been studied for purpose and requirements within the food packaging industry.

As there are no government regulations of food packaging either domestically or internationally (Thompson, R. C., Swan, S. H., Moore, C. J., \& Saal, F. S., 2009) the designs are currently determined by the size, shape, content of food within. The sheer variety of packaging shows how different these variables need to be for the food they contain. There are cardboard boxes for pizzas, clamshell containers for plated food, steam-release containers for soup, insulation to keep things warm or cold, and many other food-specific designs. The food dictates what takeaway packaging to us that not only maintains the food's integrity but also meet functional purposes to support an optimal delivery.

Beyond this, there are also requirements listed (non-exhaustively) by an article "Food packaging - roles, materials, and environmental issues" in the Journal of Food Science by Marsh \& Bugusu (2007). The first requirement is containment to maintain the food in proper assembly and/or separate as necessary, for appropriate amount of time, without heat dissipation, etc. Another requirement is to provide a biological protection from the outside elements such as oxidation, bacteria, germs, etc. Third, a package can have convenience features such as flaps, handles, lids, built-in spoons or tabs, re-sealable, reusable, or even features for distribution needs of stacking or collapsing. Finally, there are the communication requirements that provide product information and promotional graphics. There can also be sustainability considerations for environmental design, resource efficiency, end of life recovery, use of recyclable materials, etc. that help to make the packaging eco-responsible. Figure 1 showcases a range of the requirements of packaging properties. 


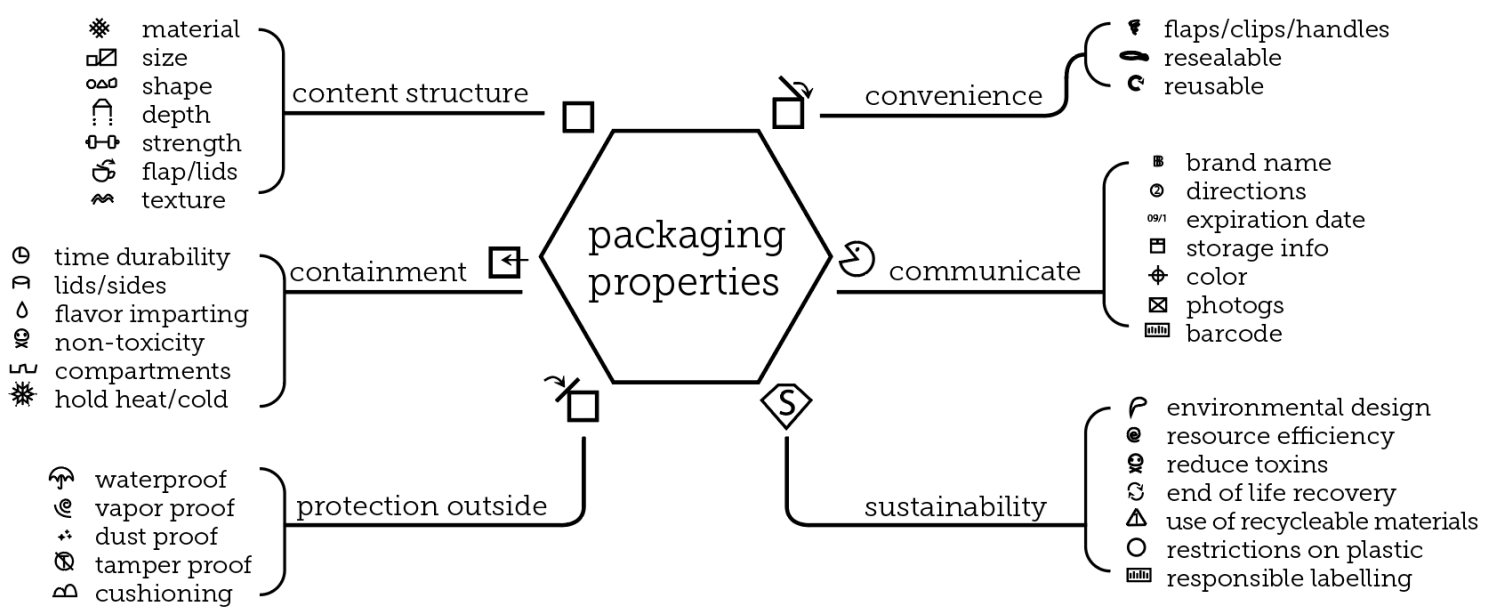

Figure 1. Packaging properties. This figure provides a diagram of the requirements of packaging properties (Martí, Sara. February 20, 2018)

Additionally, even after considering the needs of the food packaging there are also choices limited by price considerations, availability, and even aesthetic appeal (Freinkel, 2017, p. 198). Food companies themselves are responsible to determine the packaging requirements of the food they provide and package accordingly. Takeaway packaging also adapts to innovations for better food and delivery performance (Hine, 1998, p. 57). These innovations include changes in response to safety tests, consumer preferences, and ongoing trends.

\section{Plastic in Takeaway Packaging.}

Although plastic takeaway packaging is common now, it was only introduced after World War I as a suitable material for food packaging. The very first example of plastic packaging is in a polyethylene bag issued to soldiers in World War I for storing medicine (Hine, 1998). It was also employed in other food-grade experiments such as anti-rust coatings for canteen lids (Hine, 1998, p. 143). These initial uses proved sufficient at the time that plastic could be an alternative to other materials (Meikle, 1995).

Then the post-world war era heralded in the mass consumption of polyethylene in the form of another type of packaging called Tupperware (Clarke, 2001). Tupperware touted a reduction in food waste by storing leftovers and extending the shelf-life of food. Eager housewives bought Tupperware to showcase their responsible household management. As 
this plastic container became omni-present across the U.S., plastics earned a place as a suitable material choice for food packaging.

Once introduced, plastic packaging became normalized. It served as a lightweight, adaptable, shatter-resistant material in numerous applications. From lunch-boxes to Tupperware containers, cling film wrap and plastic bags, from this period onwards plastics became ubiquitous in food packaging.

Then in 1970 the reputation of plastic packaging was tainted by the first sightings of plastic litter in the ocean (Freinkel, 2011, p. 176). This prompted a backlash. Campaign advocates clamored for an end-of-life analysis for plastic. (End-of-life analysis determines how many times a material can be reused and remain viable as a material.) During this time, ecological minds also introduced the Reduce-Reuse-Recycle campaign to curb the waste. Even plastic manufacturing companies responded with educational programs and commercials that shifted the blame on public irresponsibility and individual "litterbugs" (Leonard \& Conrad, 2011).

Then in 1988 it appeared as though manufacturers were helping to support recycling process by designing a resin code classification (Terry, 2012). The resin codes would distinguish the category of plastic in the packaging. The graphic featured a chasing arrow triangle commonly used to symbolize recycling. Inside the triangle, a printed number revealed the type of plastic. (See Table 1 for a list of the graphics and these common plastic types.) However, these codes were introduced internally in the plastic manufacturing community. The purpose of the code was to help the manufacturing community categorize uses for plastic material (Freinkel, 2011, p. 177). In this way, the plastic material would be used for the same packaging purposes no matter who produced them.

However, most people are not aware of the resin code purpose and instead trust the recycling symbol as a promise that the material can be safely recycled. The confusion exists to this day, much to the chagrin of local recycling facilities who are not always equipped to handle a wide variety of plastics. 


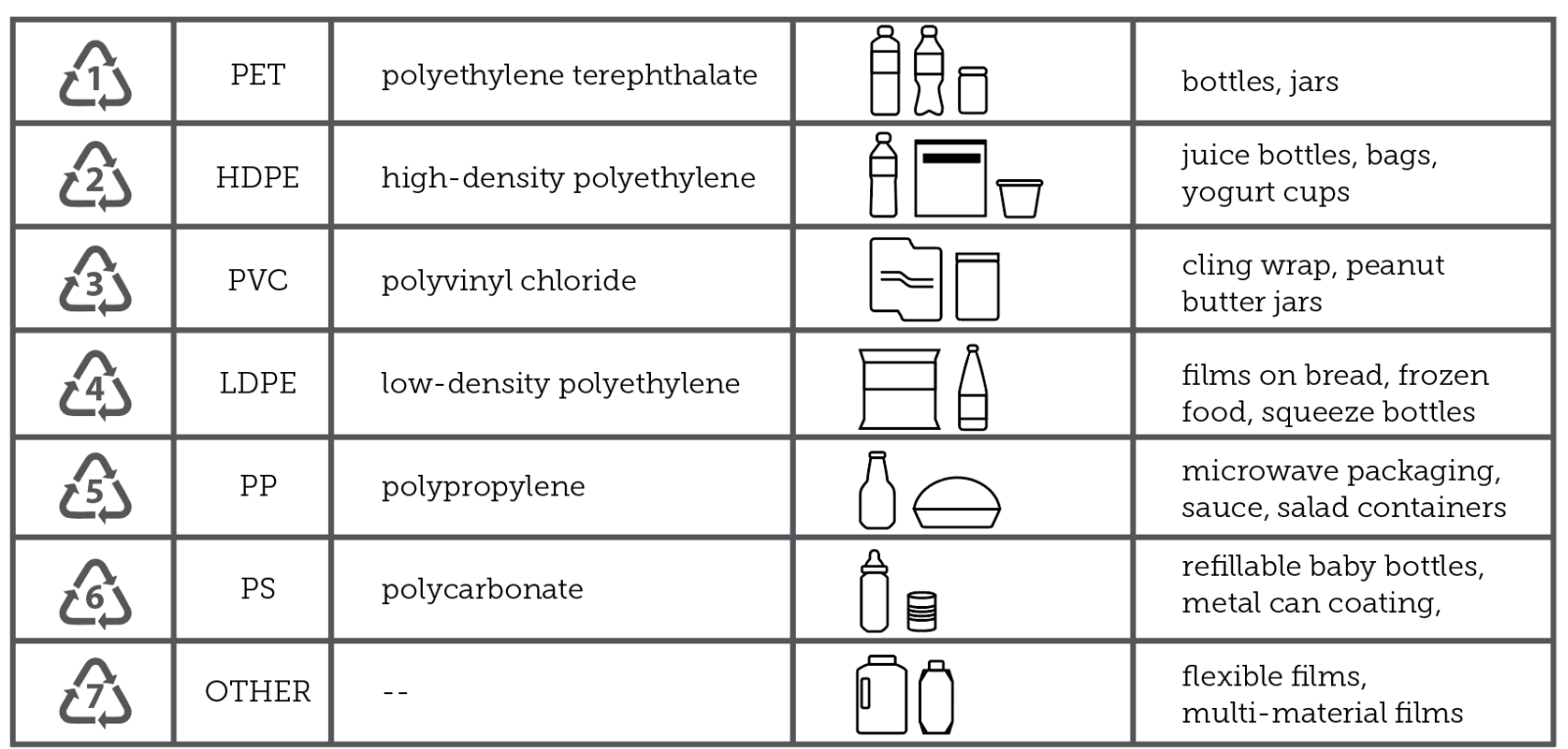

Table 1. Types of plastics. This table shows the resin codes, names and common uses of plastic types. (Martí, Sara. February 20, 2018)

Over the years, plastic has become a common food packaging material. While it is hard to estimate exactly how much plastic is currently used in takeaway packaging, Freinkel (2011) writes in her book Plastic: a toxic love story that about half of all goods are now contained in plastic packaging (p. 142).

\section{Consequences and Responses to Plastic Packaging.}

The negative consequences of plastic packaging are well-known and documented. It is not within the scope of this thesis to describe all the consequences, but it is important to quickly discuss the range of consequences on the environment, natural ecosystems and human health that informed packaging design decisions further in this thesis.

These consequences include the following:

- Plastic takeaway packaging often lives an unfulfilled life-cycle and is therefore a wasted material. (According to a 2017 National Geographic report nearly 91\% of plastics are not recovered worldwide.)

- Plastics block the natural degradation processes in landfills and create an unreasonable accumulation of trash (Wallace, 2016; Cozar et al., 2015).

- Plastic as a material has a poor end-of-life legacy. Incineration causes dangerous offgassing, landfill photo-degradation exponentially pollutes plastic in smaller pieces (Palmisano \& Pettigrew, 1992). 
- Plastics pollute when they leak out of landfills and into other terrains by wind, rain and storms.

- Uncollected plastic results in wildlife deaths. Plastic kills wildlife via entanglement (Law, 2016), as false food blocking digestion (Cedervall et al., 2012) and even as poisonous chemical accumulation of carcinogens DDT, PBB, fire retardants, etc. (Freinkel, 2011). Furthermore, plastic maliciously entices animals by soaking up a common algae-like sulphurous odor that actually attract animals searching for food (Parker, 2017).

- Plastic packaging also poisons humans, see Table 2. This poison comes from chemicals such as BPA, BPC, heavy metals, and organic pollutants from plastic packaging (Meeker, Sathyanarayana \& Swan, 2009). This type of poisoning has been shown to result in endocrine dysfunctions, hormonal disruptions and even reproductive issues (North \& Halden, 2013), cancer, immunotoxicity, obesity and immune suppression (Schaider, Balan, Blum, Andrews, Strynar, Dickinson, Lunderberg, Lang \& Peaslee, 2017).

\begin{tabular}{|l|l|l|l|l|}
\hline Chemicals & Uses & Reproductive Impacts & Cancer Impacts & Neurotoxicity \\
\hline BPA & $\begin{array}{l}\text { polycarbonates, epoxy } \\
\text { resins, polysulfones }\end{array}$ & male issues & $\begin{array}{l}\text { prostate } \\
\text { thyroid }\end{array}$ & yes \\
\hline Phthalates & plasticizers in PVC & $\begin{array}{l}\text { male issues } \\
\text { female issues }\end{array}$ & testicular & yes \\
\hline PBDEs & flame retardants & $\begin{array}{l}\text { male issues } \\
\text { female issues }\end{array}$ & testicular & yes \\
\hline Heavy metals & $\begin{array}{l}\text { polymerization } \\
\text { catalysts }\end{array}$ & $\begin{array}{l}\text { male issues } \\
\text { female issues } \\
\text { breast }\end{array}$ & yes \\
\hline
\end{tabular}

Table 2. Endocrine disruptors in plasitcs. This table shows the chemicals, uses and health impact of plastics recorded in humans based on Andrady, 2015, p. 188. (Martí, Sara. February 20, 2018)

As a result of these negative consequences, public policy and popular response have reacted in many different ways to plastic packaging. First, many countries provide recycling facilities through government services. This effort attempts to be resourceful with plastic material. However, these efforts are insufficient for many reasons. First, the wide variety of plastics are not universally created, and not equally recyclable. Second, not all facilities are equipped for the process. Third, there is a high error rate of submissions due to complicated packaging designs that contain multi-layers, different materials, and/or limited recycling prospects. 
One solution to these recycling problems is the Germany waste-management model that licenses a certification "green dot" to companies who pay for their sorting and recycling of their packaging materials (Freinkel, 2011, p. 195). This system places the recycling impetus on the companies to use a packaging with an easy end-of-life recapture. This enhances the recycling value not only to the consumer because there is a clear recapture choice (no resin code confusion there), but it also enhances value for the company as the plastics can be recovered for further reuse instead of requiring virgin-plastic creations.

Another solution is called "downcycling" which refers combining or diluting plastics into other materials to further prolong its life cycle. This response has resulted in nylon yarn, pipes, carpet fibers, and even 3D printed goods. While the intention is positive, the result is complicated since by virtue of melting the plastic it actually hinders the likelihood that the plastic will be dismantled and recycled in the future. Worse, if it is used in fabric material it can degrade human health by subjecting plastic directly onto absorbent skin tissue.

Still another extreme initiative is abstaining from plastic in daily life. Publications like the book Plastic Free and zero-waste blogs, and Facebook support groups show individuals who take on the responsibility to eschew unnecessary uses of plastics (Terry, 2012). Posts encourage habits such as using reusable bags, refillable containers, and non-plastic products (Freinkel, 2011, p. 226). This trend is catching popularity in commercial and government pursuits. In the spring of 2018 a supermarket in Amsterdam even opened a plastic-free aisle (First plastic-free aisle is an example for other supermarkets to follow, 2018).

Governments too have shown solidarity in the War Against Plastics with swift plastic reduction in the Buckingham Palace (Raphael, 2018) and even an anti-plastic straw campaign at Scottish Parliament (Use of plastic straws scrapped at Scottish parliament, 2018). In France, legislative measures banned plastic bags in markets in 2017. In 2020 future bans in France will also outlaw plastic cups, plates and cutlery (Khan, 2016).

Overall, the wide range of public policy and popular response show an increasingly contentious reaction to the problems of plastic packaging. As the "War on Plastic" gains traction, a large part of the success of any solution will have to rely on the consumer behaviors and attitude towards other packaging creations. After all, plastic manufacturing will be forced to align if consumers demand a change in their packaging needs. 


\section{Chapter 2: Examining Consumer Behavior and Attitudes}

\section{Generic Packaging Survey.}

As part of preliminary analysis of packaging, I designed and administered a generic survey online to 132 people in the months of October and November of 2017 to examine consumer behavior and attitudes regarding packaging materials, including plastic. The purpose of this survey was to better understand their preferences, self-reported habits and gauge reactions towards eco-alternative food packaging designs. The questions ranged in type and size with a variety of Likert-scale, order-preference, and open and closed questions. The survey was listed on SurveyMonkey.com and promoted on Facebook by family, friends and myself.

There are several limitations to the result. First, since the survey was administered at the beginning of my research I did not specify the survey for "takeaway packaging" as a concept. Therefore, the results may also suffer limited relevance depending upon the participant and their knowledge of my thesis. Also, there could be an implicit bias in the survey because my family and friends might feel socially obliged to participate. Then, because of my strong personal conviction about healthy eating and environmental consciousness, respondents may feel swayed to respond favorably to my opinions while answering the survey. Or, participants who would be interested or willing to do this in my network may already be aware and opinionated about packaging. These caveats being salient, the information can still be useful as an indicator of what people self-reported on their consumer behavior and attitudes towards packaging.

\section{Question and Response Analysis.}

In relevance to the purpose of my thesis I will not be analyzing each of the questions in-depth here. Instead, I will provide a short introduction of the questions and a response analysis to tabulate habits and trends. (See Annex 1 for the original questionnaire.)

Q1 started with the most important criteria for packaging material. The highest ratings brought out three top criteria in either recyclable, protection and biodegradable. 
Q1: Which of the following are important criteria for packaging material?

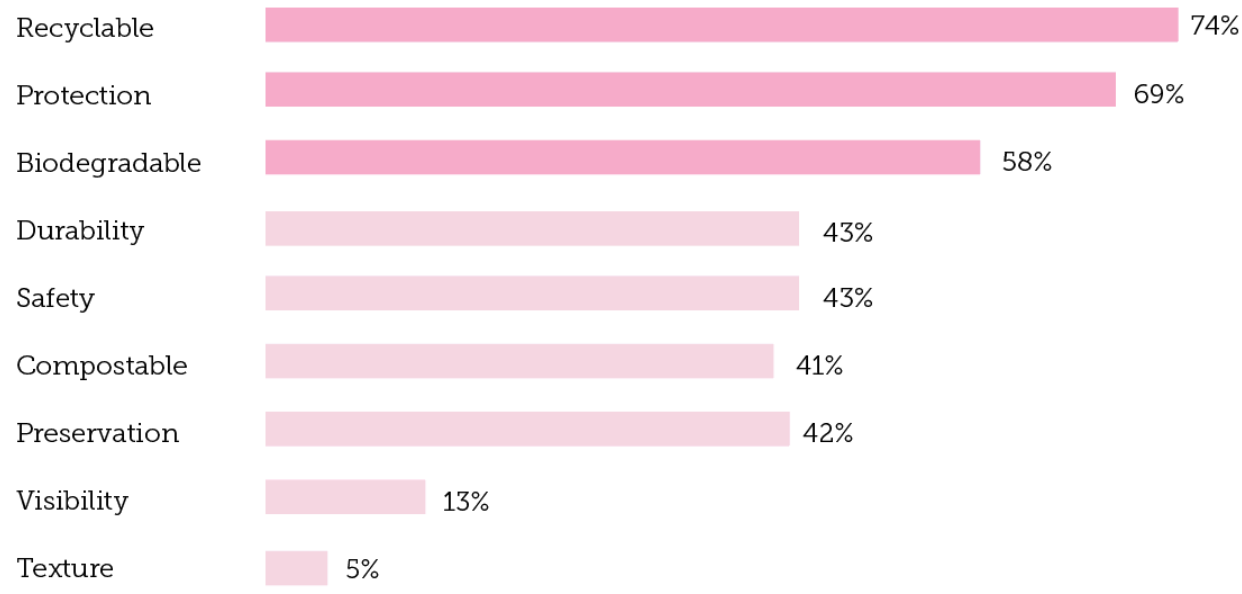

\begin{tabular}{|l|l|l|l|l|l|l|l|l|l|l|l|l|l|l|l|l|l|}
\hline & & & & & & & & & & & & & & & & & \\
10
\end{tabular}

Q2 asked how respondents decide which food (and corresponding packaging) to purchase. The highest consideration was price (73\%), followed by quantity of the product purchased (43\%), brand of the product (23\%), packaging (27\%) and brand loyalty (20\%). These responses confirms that the packaging is a mere complementary consideration when compared to the calculation of price, economic considerations of quantity and the communication of brand quality. Price, quantity and quality factor higher than the means by which it is stored, transported or carried.

Q3: Rate the influence of the product elements according to how it influences you to buy a product?

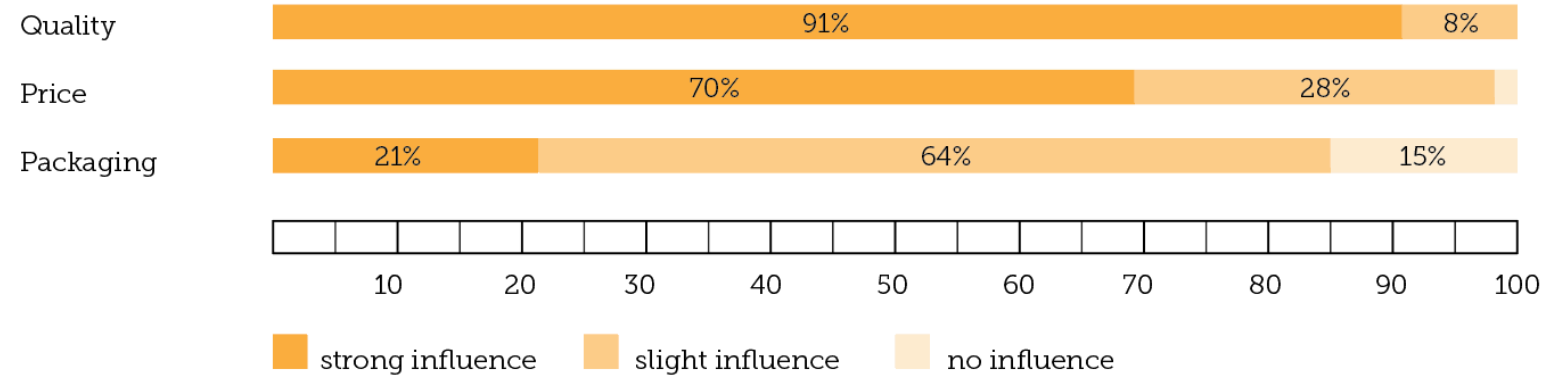

Q4 focused specifically on how strongly does packaging influence the buying decision when purchasing food products. In this case, respondents reported that packaging influences the majority of the participants $94.54 \%$ in their purchase decisions. Only $5.47 \%$ of the respondents admitted to no influence at all for packaging.

Q5 asked respondents to rate the materials according to preferences. However, the results of this varied widely in relationship to availability and preference. The only relevant 
answer was in the analysis of plastics where results show a high acceptance of ecologically minded materials and a rejection of plastic that coincides with sustainability trend. In the results of this question $42 \%$ reported the lowest preference to plastic as food packaging material. Highest preference resulted in biodegradable, compostable and glass as the most preferred packaging materials.

Q5: Rate the following materials according to your preferences on food packaging:

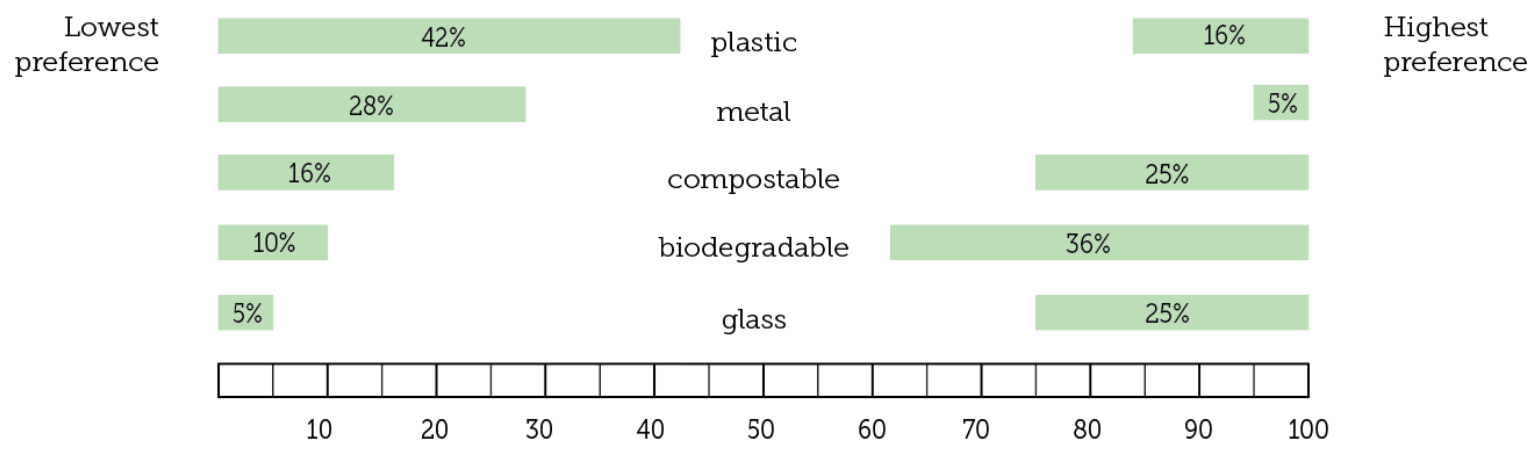

Q6 asked for a rating on a Likert scale regarding how important is packaging to the respondent when choosing a food product. The majority (93\%) rated it as important. However, this contradicts previous questions on preferences.

Q7 then asked for rating on the Likert scale regarding convenience and how important it is to the respondent when choosing a food product. Tellingly the majority (97\%) rated convenience as important factor as well. There seem to be many competing concerns when purchasing food products.

Q8/Q9/Q10 requested the current frequency at which respondents prefer materials when buying food products.

Q8/Q9/Q10: Current frequency of preference of materials when buying food products?

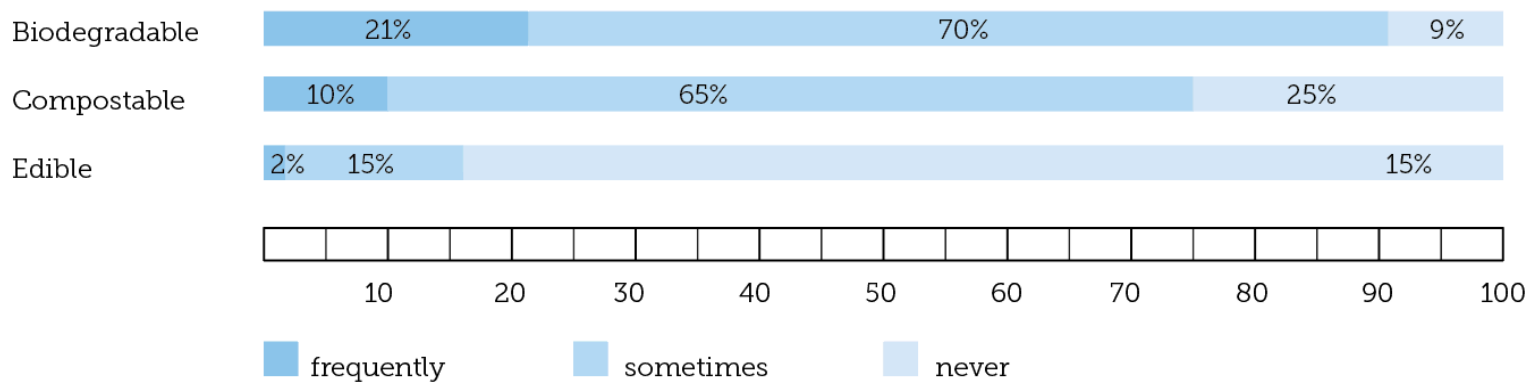

Q11/Q12/Q13 requested the current projected frequency at which respondents prefer materials when buying food products. 
Q11/Q12/Q13: Current projected frequency of materials when buying food products?

Biodegradable

Compostable

Edible

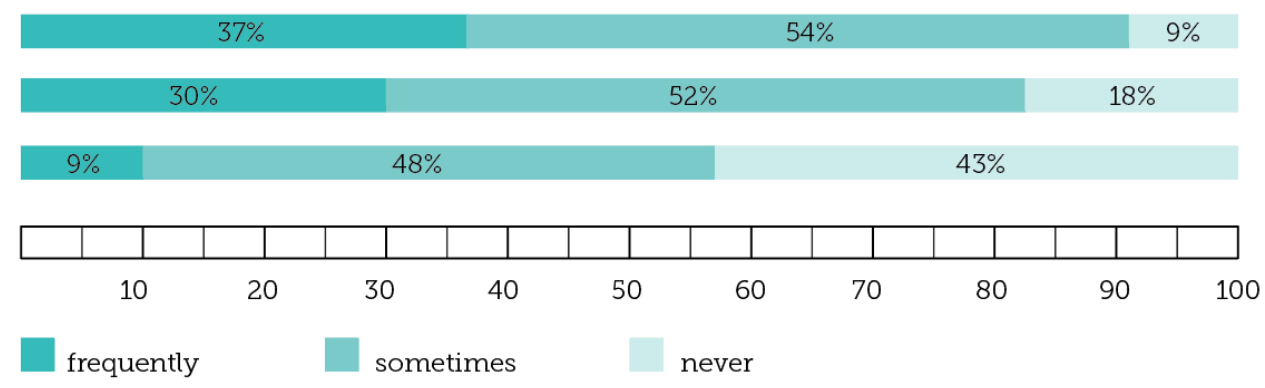

Q14/Q15/Q16 requested the past calculations at which respondents preferred materials when buying food products.

Q14/Q15/Q16: Past frequency of preference of materials when buying food products?

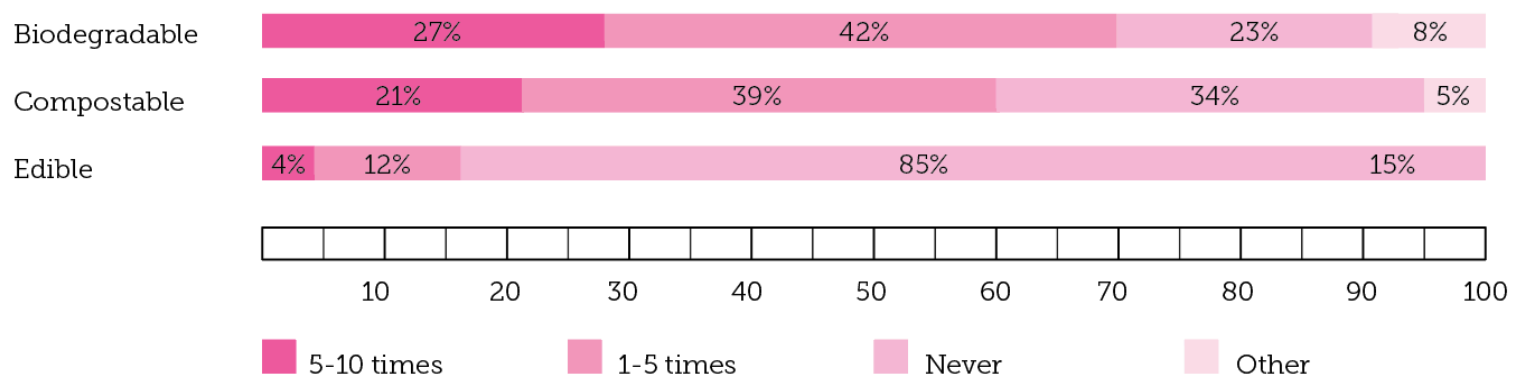

Q17/Q18/Q19 requested the future projected calculations at which respondents will prefer materials when buying food products.

Q17/Q18/Q19: Future projected preference of materials when buying food products?

Biodegradable
Compostable
Edible

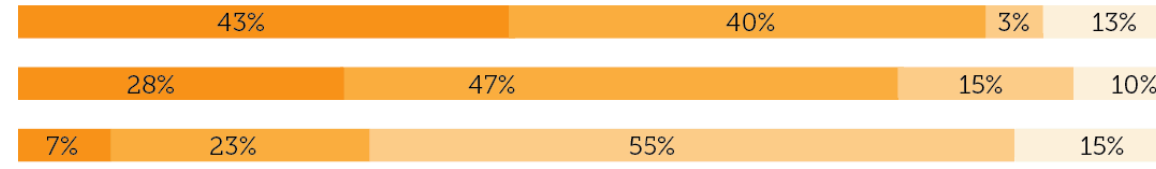

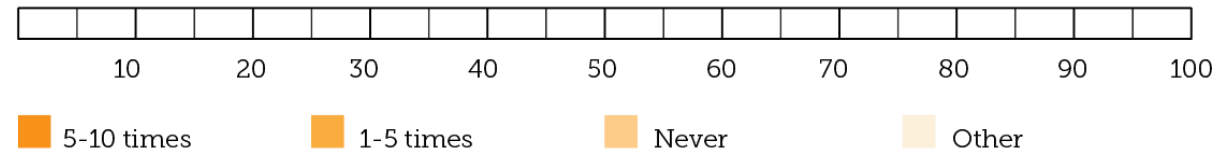

Q20 was an open question regarding personal feelings about biodegradable packaging materials. The answers categorically can be divided in response as 93 who reported general positive feelings for the idea, 11 others who expressed their personal intents or a pledge to change their habits, 17 who were either unaware of the material or wanted to know more, and 11 who expressed indifference or other hesitations. 
Q21 probed the personal feelings of respondents about biodegradable packaging materials in an open-question. After categorically dividing the answers, 82 respondents had generally positive feelings and reactions, 27 expressed had hesitations or conditions regarding the material, 8 respondents were indifferent and 1 was in clear opposition. 5 responses were discarded due to inadequate information.

Q22 was another open-question regarding personal feelings about edible packaging materials. Responses after categorization yielded: 39 were curious and wanted more info, 27 fostered negative responses, 21 shared positive responses, 15 respondents specifically used "weird" when describing their feelings, 9 respondents expressed hygiene/sanitation concerns, 2 stated indifference and 9 answers were discarded as incomplete and/or undecided. Clearly, edible packaging causes many to feel curious or uneasy. The use of "weird" suggests a general feeling of mistrust and the words gross, strange and even an unhappy emoticon show that the edible packaging will have to overcome serious hurdles in order to be accepted.

Q23 was a biographical data showing that 19 respondents were male, and 111 respondents were female. Q24 captured age range for respondents with 0 respondents younger than 15 years of age, 24 respondents between 16-25, the overwhelming majority of respondents (63 total) were between the ages of 26-35, 24 respondents between 36-45, 8 respondents between 46-55, 9 respondents between 56-65 and only 1 respondent categorized as 66 and above.

Q25 requested self-report of yearly income. Of the respondents, 23\% earn less than 10,000 euros, $23 \%$ earn between 25,000-49,999 euros, 19\% earn between 50,000-79,999 and $25 \%$ earn more than 80,000 euros.

\section{Results Condensed.}

There were several contradictions in the results. While people claimed to show a consideration towards packaging materials (Q1 and Q6), the food choice-questions (Q2 and Q3) highlight that it is a secondary factor in their food-purchasing decisions. This shows that it might not be as important in purchasing choices for the vast majority, although they do have a preference when other food purchase needs are not considered (e.g. price, quality in Q1 and convenience Q7.) It would be interesting to know at which point they consider the packaging as critical and further qualitative information could help explain their preferences.

Another interesting result was how high recyclable packaging materials were rated as purchasing criteria in Q1 in comparison to biodegradable or even compostable packaging. This may be due to the lack of clarification that recyclable materials in that question did not 
include food-safe items like glass, which is technically recyclable. Or the result could be due to still preconceived notion that all plastics with recycling resin-codes and recycling symbols are actually recycled. So, it would be more interesting to ask consumers if they considered plastics as the only recycling material for that question, and furthermore if they know which items can actually be recycled according to their local waste treatment facility. However, when compared to rating material results from Q5, there seems to be an awareness of plastics being poor recycling option. In that question, most respondents preferred biodegradable, compostable and glass before even considering plastic. That might indicate that people are aware of the recycling options, or that plastics are waning in popularity, or that people are more conscious about plastic packaging causing health problems. Further insight would be helpful.

Past (Q14, Q15 and Q16), present (Q8, Q9 and Q10) and future (Q11, Q12, and Q13) projected behaviors yielded stunted results. The percentage of past consumption and future consumption show greater preference for biodegradable, compostable and edible packaging than in present situations. This was highly confusing since it did not confirm growing consumer consideration for responsible packaging. Maybe the repetition of the successive nine questions confused or annoyed survey participants. Or the result could be due to the reality that the past or future experience is easier to quantify in reflection in current situations. Further insight would be helpful in cataloguing the actual amount vs the reported amount of consumed packaging in each of the three categories.

In the final series of open-ended questions regarding proposed packaging creations, participants overall seemed positive, eager and interested in biodegradable and compostable versions. However, when the questions pivoted to edible packaging, the majority of responses were negative citing sanitary inhibitions. In some cases, the word "weird" or "gross" were used to describe their discomfort and a general uneasiness about the idea. This could be due to the simplicity by which the question was posed as it did not offer contextual information to help guide the respondent. However, maybe it shows that edible packaging is not socially acceptable or appropriate. Or instead that these radical design ideas require exposure and sampling to change public opinion. 


\section{Chapter 3: Definitions and Alternatives Inspiration}

\section{Definitions of Alternatives.}

To start these descriptions, it's important to distinguish the categories of the designs that I chose to research. Originally, I had intended to use biodegradable, compostable and edible. However, I have since changed the categories to industrial-compostable, homecompostable, and edible categories as shown in Table 3.

\begin{tabular}{|l|l|l|}
\hline Packaging Type & Definition & Testing \\
\hline Edible & food grade safe for humans & human consumption \\
\hline Home Composting & home compost safe materials & home compost \\
\hline Industrial Composting & $\begin{array}{l}\text { earth-safe materials certified } \\
\text { for industrial composting } \\
\text { processes }\end{array}$ & *incomplete \\
\hline
\end{tabular}

Table 3. Packaging Types. This table shows the packaging type aspirations, definitions and the testing methods. (Martí, Sara. February 20, 2018)

I eliminated biodegradable as a category because the Federal Trade Commission (FTC) of the U.S. (2017) defines biodegradable in vague terms. Their definition deems that biodegradable is a type of material that will break down and return to the earth in a natural process. However, the FTC does not specify the time duration, the use of earth-safe material, or even what a "natural" process entails. So, the term "biodegradable" is rather ambiguous and unhelpful. Since my research is to create packaging designs that are not harmful, biodegradable cannot be one of the design categories as it does not prohibit the inclusion of problematic packaging materials that are earth-safe.

Instead, I am using the term industrial-composting as a category since it implies that products are earth-safe materials but are so removed from daily house-composting that they deserve their own processing facility. These facilities provide machine mixers and are heated to high temperatures. Industrial composting facilities are different from home-composting because this process is a more intense and productive aeration and break down process (Thompson, 2018) than a home compost bin. 
This category allows me to highlight many bio-plastics (including ethanol and sugarcane) that require industrial composting and have been championed as partial biosolutions (The New Plastics Economy, 2016). These bio-plastic hold comparable shape and texture to common food packaging plastics and yet can be industrially-composted back to soil within several months.

I would like to note that this category is slightly misleading since although it is a solution, it is not a ubiquitous solution since industrial composting requires a separate collection facility that does not exist in many communities or even countries. However, industrial composting might be used as a gateway fix that encourages further solutions and is in the meantime better than using plastics in terms of toxicity (negligible), material (natural), and life-cycle (averaging 200 years to biodegrade outside of appropriate facilities).

Compostable and edible are easier to define. For my definition purposes, compostable includes packaging that degrades in a home-composting facility. This requires that the product be made of food-grade material or organic matter such as plant material. In essence, any material that is safe for home-composting without leaving any toxic residue. Edible creations are further simplified into packaging products that are food-grade safe for the purpose of human or animal consumption.

\section{Inspiring Packaging Examples}

There are several inspiring packaging examples that are worth highlighting. Since the category of industrial composting is commonly known, I will only be showing design in the home-composting and edible categories. While each of these design show a different process and expertise, they all attempt to replace harmful materials like plastic in packaging.

The home-composting creations shown in Figure 2 include Avani Eco company cassava-based bio-plastic bags, the 360-paper bottle, and Ari Jonssón's red-algae molded bottle. In comparison to the industrial designs, these creations vary in the manufacturing capabilities from professional to student-work. Yet they still highlight new breakthrough creations

The first design is a cassava-root based bio-plastic bag created by Avani Eco in Indonesia. The founder of the company Kevin Kumala is a biologist and he took three years to design a lab-scale method to create a compostable bioplastic for full-scale mass production (Kumala, 2017). The company provides a range of cassava-based products including takeaway containers. In an effort to assure people of the safety of the products, Mr. Kumala is shown in several promotional videos ripping strips off the bag, melting it in hot water and 
drinking concoction to demonstrate the non-toxicity of the compostable product (Escobedo, 2017).
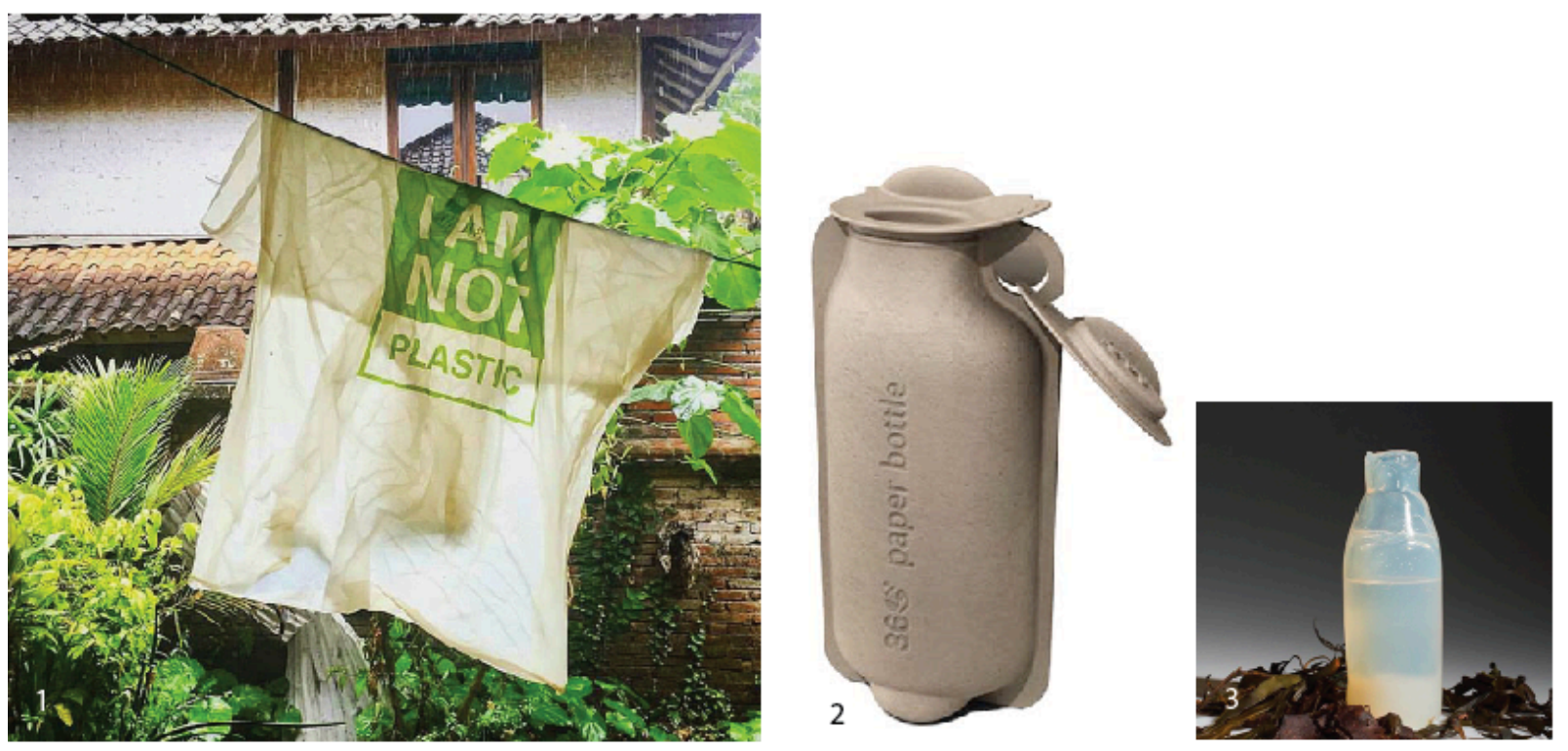

Figure 2. Photos of three home-composting examples of packaging. 1: Avani Eco "I Am Not Plastic Bag" (Gozdanic, 2017), 2: 360 Paper Bottle (Baranovska, 2010), 3: Ari Jónsson Red Algae Bottle (Morby, 2016)

Another design is the 360-paper bottle is a pressed flat bottle fashioned out of paper mold that holds water with a screw-on lid (Paper Water Bottle website, n.d.) Created by designer Jim Warner in New York in 2008 the flat bottle has only just recently started production in February 2018 after a Kickstarter foundation in August 2017 which brought the design to life. The packaging is created out of paper pulp and biodegradable resin and claimed to break down in home composting system within several months.

Ari Jonnsón created the next packaging as a bottle made out of red-algae frozen in a mold. This water bottle was a designed by a student in Product Design studies in 2017 at the Icelandic Academy of Arts (Cohen, 2017). Using red algae powder, Jonssón designed the bottle to be mixed with water and frozen in a mold. Once completed, the bottle is released from the mold and filled with water. The water maintains the structure of the bottle and once the bottle is emptied the red algae naturally begins to decompose and disintegrate perfectly, barely needing a home-composting system (A Student In Iceland May Have Just Saved The Planet, n.d.).

In edible packaging creations there has been a trend in companies pursuing fruitsskins and even abundant but underutilized food products. This includes products such as Wikipearls yogurt skins, Loliware seaweed-based cups, Tomorrow Machine sugar-oil casing, 
and Evoware algae-films as pictured in Figure 3. Each of these packagings serve food packaging purposes of containing a food product (such as oil in the case of Tomorrow Machine, or liquid as in Loliware cups.) However, some of these edible packagings cannot extend their use for take-away packaging (containing whole takeaway meals, e.g. sandwich.) Still, they highlight the creativity and limitations of edible design packaging and are therefore included.
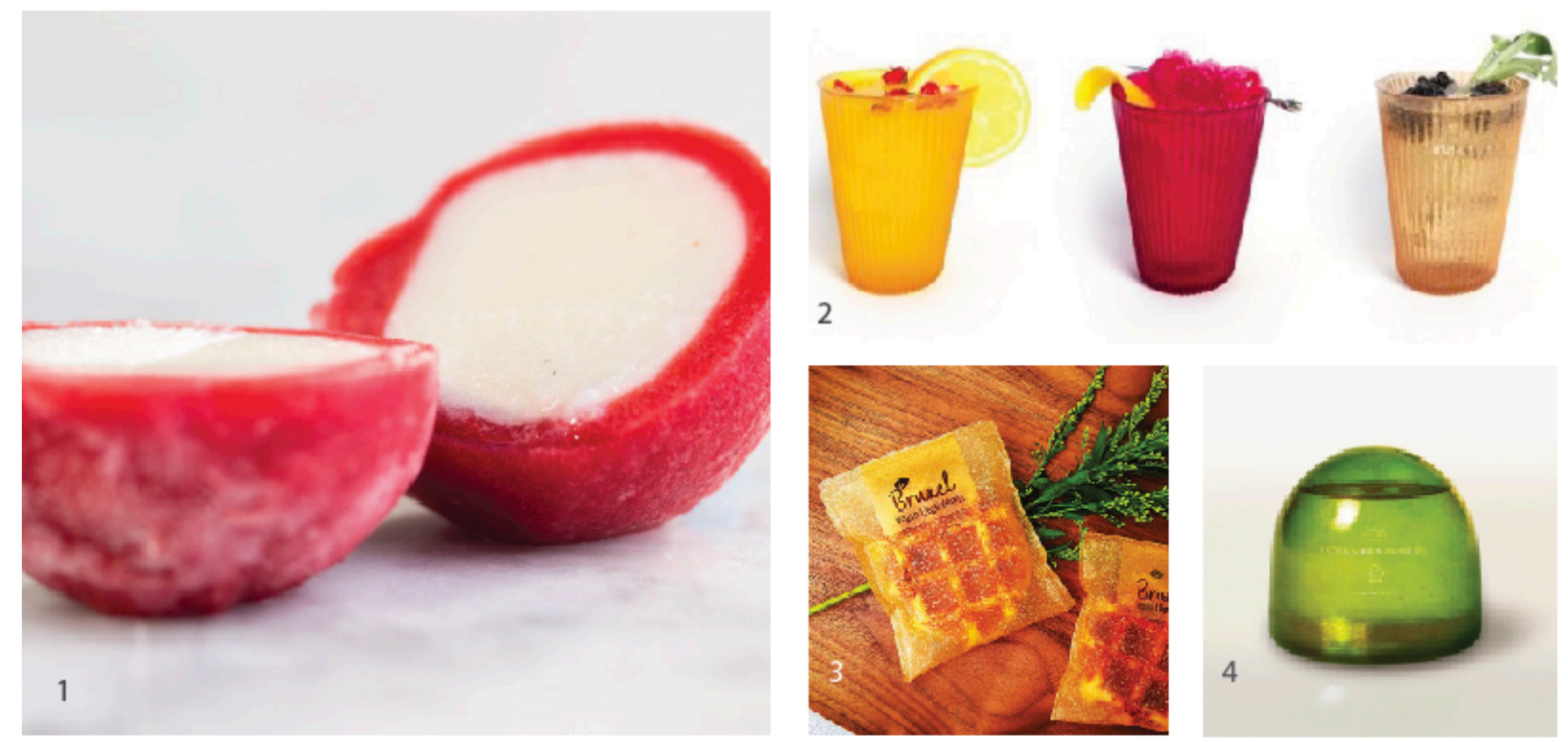

Figure 3. Photos of edible packaging. 1: Wikipearl (Stonyfield and Wikipearl, Inc, 2014), 2: Loliware Cups (Loliware/Amazon.com, 2016), 3: Evoware Seaweed Sachet (Evoware/NowJakarta!, 2018), 4: Oil encased in sugar dome packaging (TomorrowMachine, 2015)

WikiPearls are made out of nutritive ions and polysaccharides to cover food in the same way fruit skins do like a mochi gel on a Japanese ice cream (Pecci, 2014). No bigger than a plum, the product is created by Harvard Engineering professor Dr. David Edward and is currently being used in partnership with Stonyfield Farm's to create Frozen Yogurt Pearls. Ironically while the product is available and widely distributed throughout the U.S., the product is still encased in a bioplastic bag. In an NPR show, radio hosts posited that customers don't seem ready to accept the food sans packaging just yet (Evans-Brown, 2014).

Loliware is a fruit-leather and seaweed cups in flavors such as vanilla bean, tart cherry, yuzu citrus and matcha green tea (Hoyt, 2017). Loliware creators and industrial designers Chelsea Briganti and Leigh Ann Tucker created their cups as a way to avoid the common 33B plastic cup that end up in landfills. The cups themselves are served with a compostable paper sleeve to enable easy holding and serving. The cups can be used and 
reused for up to 4 hours with liquids. They can be eaten at room temperature and any part left uneaten is completely compostable. In late 2015, Loliware won investment banking in a very public U.S. TV show called Shark Tank (Season 7 - Episode 2, 2015). Currently, the cups are sold on Amazon.com and at some U.S. based retail spaces. In December of 2017 Loliware launched a Kickstarter for a spin-off creation called Lolistraw as an edible straw to provide an alternative to the single-use throwaway market.

The next designs are by Swedish design by two designers Hanna Billqvist and Anna Glansén from a small studio called Tomorrow Machine. They created a series of packages based on the priority of self-destructing and biodegrading naturally (Edible, 2015). The first is a dome-shaped made out of wax coated sugar which contains oil. It can be opened by cracking the "egg" like top. Once emptied, the sugar-based packaging melts naturally in water. A second creation is a smoothie made of agar-agar seaweed framed in a mold and meant to package cold drinks. Unfortunately, I am unable to find information whether the products are mass produced - all online presence ended late in 2016. However, their designs show a perfect packaging future where once the products are consumed the package is quickly and easily eliminated.

Finally, there is also the forward-thinking company of Evoware. Evoware is led by David Christian and Edwin Aldrin Tan in Indonesia who are creating a packaging film by utilizing ubiquitous seaweed (Schiller, 2018). The packaging won a \$1 million Circular Design Challenge by the Ellen MacArther Foundation for solutions for small or complex unrecycled problems (Peter, 2017). This packaging is created by molding algae-based plasticizer into sachets that can house seasoning, sauces or flavors. Since the package naturally biodegrades in water, these packages can be dropped directly into the cooking and mixed in. Evoware also creates a range of products with this seaweed mix including food wraps, coffee sachets, and even dry-seasoning sachet (Evoware website, n.d.).

\section{Chapter 4: Eco-designs and Workshops}

\section{Design Methodology.}

My methodology for the design process can be described in three separate phases as seen in Table 4. Phase 1 required an analysis of a take-away food choice and the life-cycle prospects. The life-cycle prospects help me consider how long the packaging container needed to exist according to what is contained within. (Not to be confused with life cycle assessment which is the technique used to assess environmental impacts associated with the life of a material from extraction to use, disposal or recycling.) 
In Phase 2, I explored materials and processes in order to bring the design into fruition. This includes any material-making, cooking and finishing processes. Finally, Phase 3 concluded with a series of live-product testing in workshops using human-centered design (HCD). This research provided focus-based testing methods to assess human needs and uses in an interactive testing space.

\begin{tabular}{|c|l|l|}
\hline Phase & Description & Analysis explanation \\
\hline Phase 1 & Analysis of takeaway category & $\begin{array}{l}\text { 1. category: bowl, bento, clamshell, } \\
\text { 2. food needs: shape, form, texture } \\
\text { 3. packaging requirements: collapse, flap, etc. } \\
\text { 4. life-cycle: hours vs days, simple vs repeated }\end{array}$ \\
\hline Phase 2 & Creation & $\begin{array}{l}\text { mixing, dehydrating, mold-making, material-fold- } \\
\text { ing, setting, 3d printing }\end{array}$ \\
\hline Phase 3 & Human-centered design & $\begin{array}{l}\text { full-scale models presented for use } \\
\text { Mid-use descriptions and testing } \\
\text { post-use qualitative survey }\end{array}$ \\
\hline
\end{tabular}

Table 4. Methodology phases of design. This table shows the three phases used in this thesis for packaging design. (Martí, Sara. February 20, 2018)

This three-phase methodology helped me research needs and creative methods as well as iterate responsively on designs based on feedback from workshops. This methodology was in no means static since each creation overlapped another in the research process.

Before continuing, I would like to state some of my limitations as a researcher and this research topic. First, I made the scope of the thesis project broad by including three categories of industrial-composting, home-composting and edible designs. Since each category has its own requirements, materials, creation processes, etc. my time was divided for the creative process. Despite my efforts, I was only able to complete the edible design concept in time for the thesis publication. Future studies may benefit from limiting the scope or tightening time management techniques.

Another limitation is that I am not skilled or trained in the scientific backgrounds of either nanotechnology, biology, chemistry, engineering or even industrial design. Therefore, there are extreme learning disparities in my expertise and experience that likely limited this project and could greatly benefit from further refinement by other like-minded researchers.

This ambitious project also suffered an obvious time limitation because the purposes of designing, testing and refining stages were condensed into a two-and-a-half-month period. 
Longer time periods could provide a more fruitful research and discovery process for the creation and testing phase.

Despite these limitations, I was able to complete the methodology to design, test and refine a packaging design for only one eco-alternative category: edible. I felt personally compelled to start with this category because it was so poorly received in the online survey. As stated in Chapter 3, edible packaging would include food-grade safe material suitable for human or animal consumption.

\section{Edible Creation.}

For phase 1, the packaging choice was guided by the natural limitations of the food grade materials. Since the majority of the preliminary research yielded open cups and small edible bowls, it seemed appropriate to pursue similar designs. After sketching and considering several design takeaway packaging ideas (see Figure 4) the best idea resulted in a rounded edge dish with a stretchable lid. 


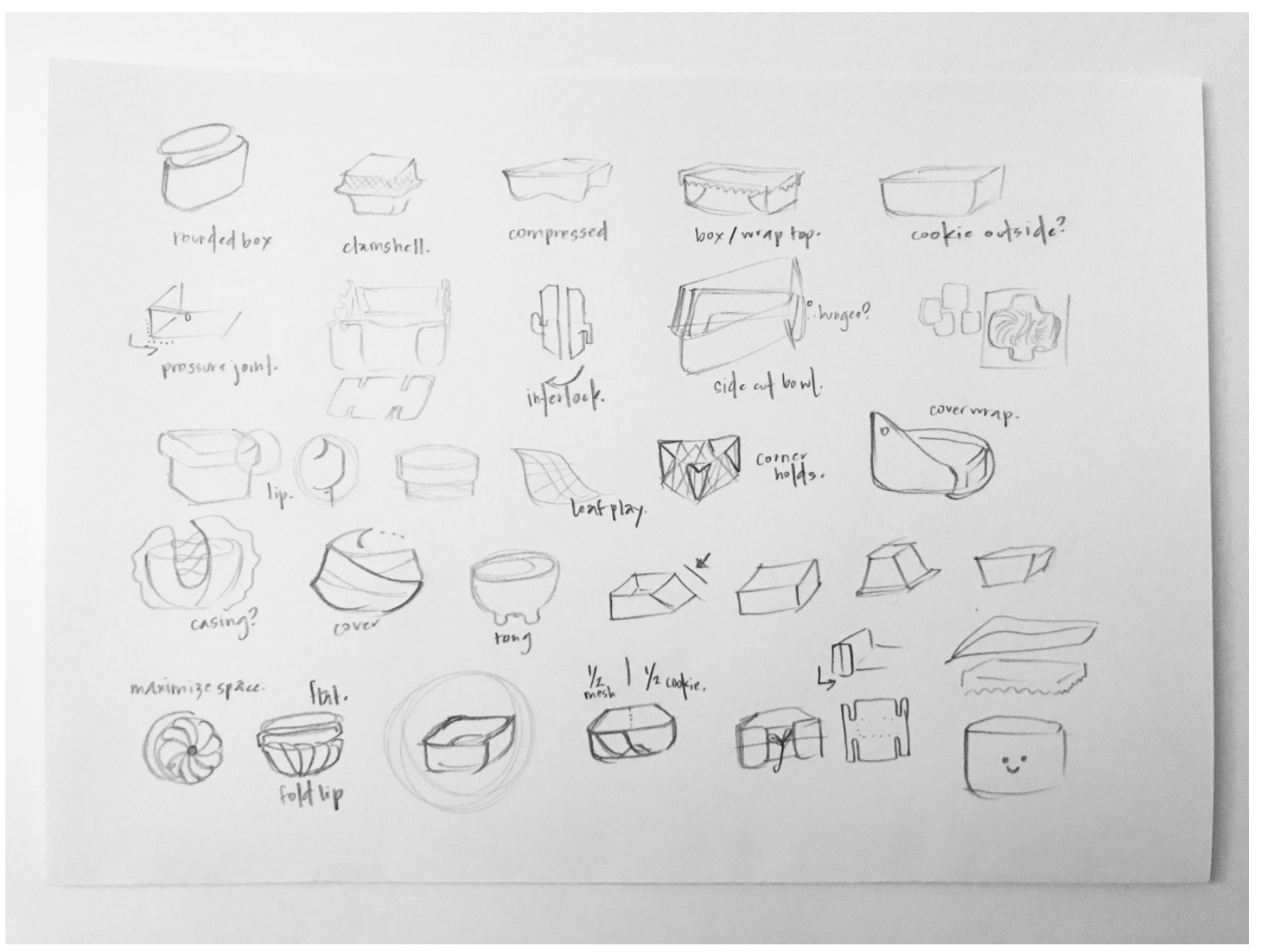

Figure 4. Sketch ideas. This image shows a variety of designs imagined for packaging design. (Martí, Sara. January 15, 2018)

The life cycle prospects for this edible takeaway packaging required that the bowl have a "life" that could last for several hours after purchase to be either consumed along with the food or just after the meal. After testing grains such as quinoa, chia, rice and sesame in mixtures recommended from raw food cookbooks I found a possibility in flaxseed. Flaxseed resulted in a sticky texture perfect for spreading onto a mold. Additionally, I used a dehydrator as a low-drying process conducive to the design creation.

In phase 2 , the design went through successive iterative processes. First, I created the recipe and process for the bowl (see Figure 5). In my initial attempts to use the mold, I spread it too thick which made it difficult to slide out the bowl. However, by changing the mold to a smoother bamboo plate I was able to slide the bowl out easier. Then, the first drying test toasted the bowl and left it brittle and weak. In subsequent attempts the temperature was too low and the bowl fermented. After adjusting the temperature to $40^{\circ} \mathrm{C}$, the best process tested was to dry the bowls one night in the mold, and the next night outside of the mold. 
Next, adaptations were made to the mold by heightening the rim to accommodate deep dish needs. This was done by extending the mold internally with a hard sheet of paper which created a concave design. In the next test, I extended the mold externally which provided me a ridge that was thin and crusty.

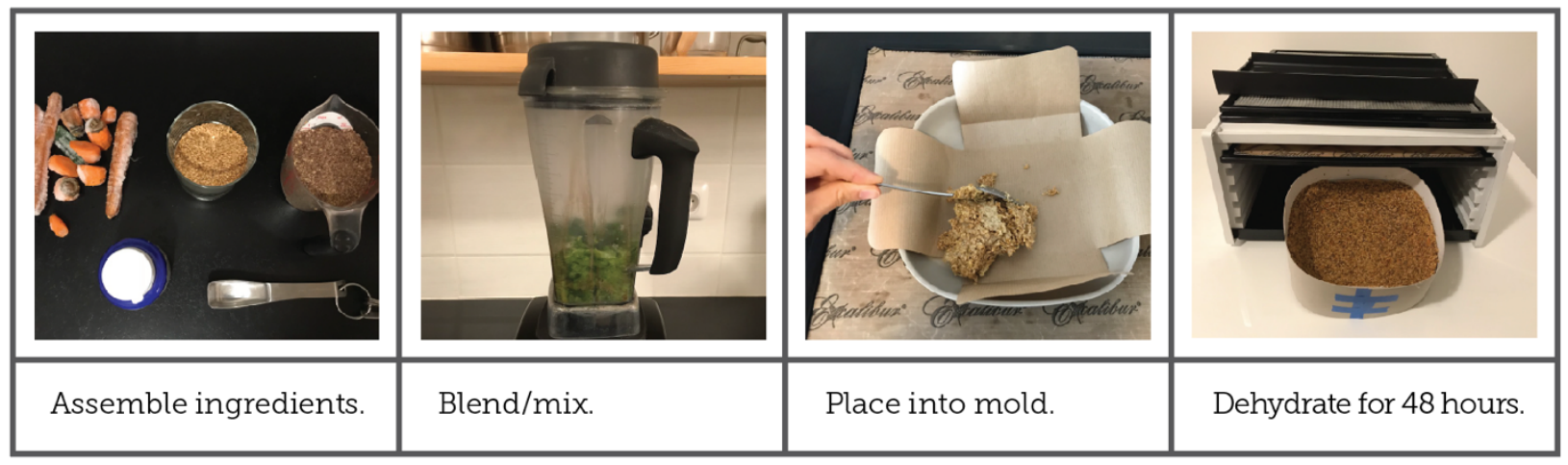

Figure 5. Edible bowl recipe instructions. This figure is an instruction photo strip showing progressive steps in the recipe of the edible bowl concept. (Martí, Sara. March 30, 2018)

The flexible packaging cover was first tested with agar-agar, incorrectly mixed with water and banana. (Agar-agar works only by being diluted in hot water.) In further tests I learned to whip low, lower the water content and shake and settle the mixture to reduce air bubbles. In further adaptations the best cover was a banana dehydrated on low-heat for 24 hours at $1 \mathrm{~mm}$ thickness (see Figure 6).

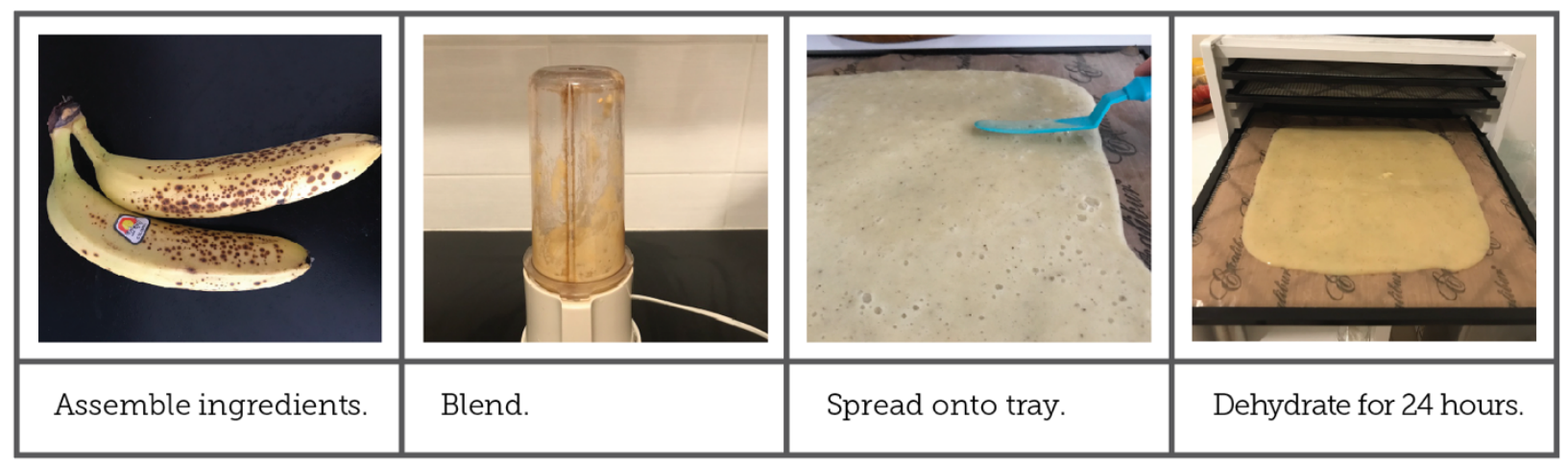

Figure 6. Edible cover recipe instructions. This figure is an instruction photo strip showing progressive steps in the recipe of the edible cover concept. (Martí, Sara. March 30, 2018)

Finally, the testing in phase 3 consisted of workshops in classrooms at Paris College of Art (PCA) and quick taste-test interviews during my artist residency at Carrefour Numerique $^{2}$ at Cité des Science et de 1'Industrie. In the classrooms at PCA I tested full mockups with a total of 10 students. For the first tests I plated the food into the packaging from a local restaurant. In subsequent tests the local restaurant consented to plate the food directly 
into the packaging from their counters. In these full mock-up tests, I was able to provide students with compensation for participation (via the food in the packaging), test the strength and durability of the packaging (by plating the food directly into the packaging) and conclude with qualitative interviews.

The results of each testing also informed the iterative process. In the first test, the packages either leaked because of porous seeds or collapsed. This was solved by changing the blend of seeds as $1 / 2$ meal and $1 / 2$ seeds for a better bind. Then, the plate was too shallow, so the plate was extended through a mold-adaptor described above. Next, participants requested a hygienic wrapper for holding the packaging, so the packaging was fortified by a sheet of Kraft paper. However, subsequent modifications cut away the paper until a short cross strip seemed most suitable. The final result was voted by participants as hygienically convenient to hold by one or two hands, to place on a desk or surface, and to eliminate grease-transfer on fingers for multitasking activities while eating.

Following this I hosted taste-tests at Carrefour Numerique ${ }^{2}$ where I was able to refine flavor and texture preferences through mini-samples. Since the location is targeted towards children, I administered the workshops family-style with parents and children at the same table. After compiling their preferences, I modified the ingredients ( $1 / 4$ flax-seeds to $3 / 4$ flaxmeal mix) and prioritized the blended carrot flavor (it was the most popular.)

There are several limitations in the creation of the edible design. First, ingredient quality, temperature and humidity can affect the design with inconsistencies in the baking process. Second, there is also a moral consideration of using food-grade materials for anything other than food. While these limitations do exist, I believe that the packaging could be a useful and purposeful application in the case of once-in-a-while indulgences no different than an ice-cream cone. When purposeful and used fully this packaging could provide a novelty delight for enthusiastic consumers. Moreover, it contributes negligible waste in comparison to plastic packaging. (See Figure 7 and 8 for final edible takeaway food packaging concept.) 


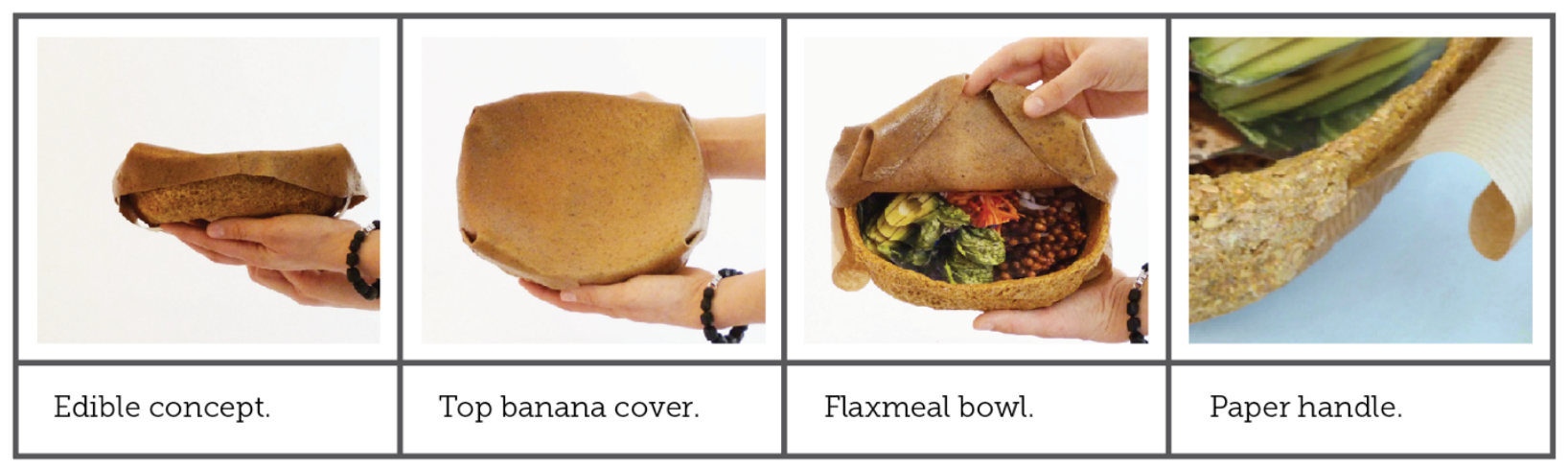

Figure 7. Finished edible concept. This figure features a strip of photos showing the side, front, inside and detail of the edible takeaway food packaging concept. (Martí, Sara. March 30, 2018)

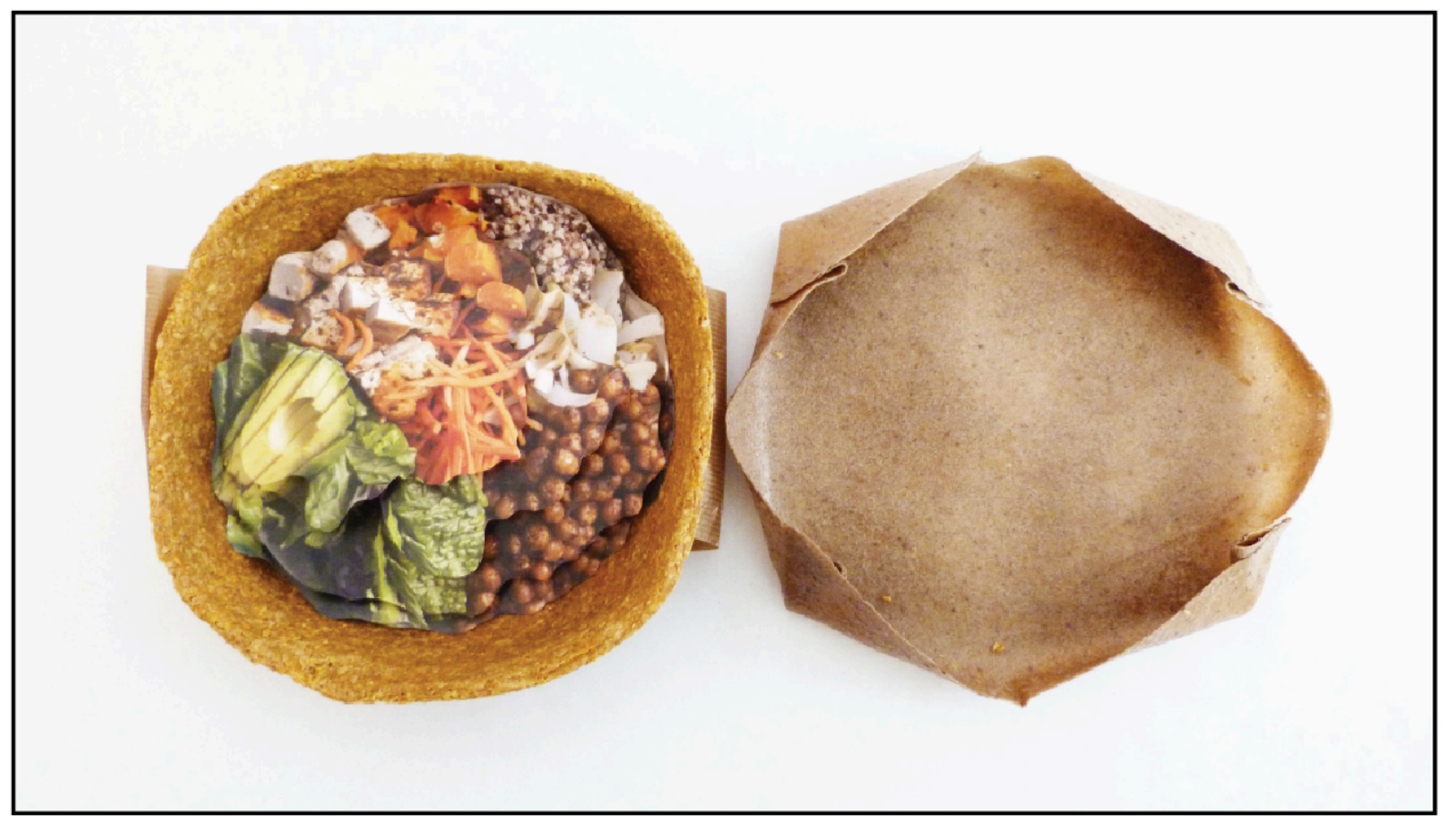

Figure 8. Aerial view of finished edible concept. This figure shows the edible food packaging concept bowl and cover in an aerial photograph. (Martí, Sara. March 30, 2018) 


\section{Conclusion}

Packaging is a complex design system requiring tremendous creativity and utility. This thesis project attempted to address packaging by shedding light on the limitations in plastic packaging as well as exploring eco-alternatives proposed by other designers as well as my own creation. In completing this thesis, I have several conclusions about the results.

First, it is important for me to address my limitations as a researcher. It is critical to note that this study suffered from the lack of scientific-based background in nanotechnology, biology, chemistry, engineering or even industrial design that would have aided the proposals and the results. For future studies I would highly encourage the collaborative efforts of mixed background researchers in order to overcome these limitations in expertise. In addition, further research should be done within the manufactured processes to obtain more consistent results. Obviously, a longer research time-frame would also be beneficial.

Despite these limitations, I was able to glean some results to further advance this research topic. First, there is a clear dependence on packaging convenience for the impromptu takeaway culture ingrained in our present-day lives. The results of my survey and conversations in testing phases helped to highlight the ways in which convenience plays a part in our daily packaging choices and how consumers will continue to demand take-away packaging that can fulfill this need. Convenience trumps many other considerations and was repeatedly mentioned as a critical quality when accepting packaging choices imposed by food services. This will be a difficult challenge to meet when introducing eco-alternatives to takeaway packaging.

Second, the packaging industry seems to be unprepared or halting in their manufacturing changes to cater to sustainable packaging demands. Publications such as the New Plastics Economy report, Packaging Digest and circular mentality reports all admit the problematic nature of plastic material. Their internal stories and conversations echo sentiments from consumers and urge innovation and development. But the progress seems limited and internally discouraged because of costs and a lack of viable alternatives.

Third, as noted in my research, there is a burgeoning new industry for alternative packaging designs. However, they are severely limited in number and quality to sufficiently elevate alternative packaging options sustainably. This small pool may also self-sabotage a wider packaging switch since even if takeaway food companies want to provide sustainable packaging options, they are limited by a lack of choice. On the other hand, the scarcity of 
options may provide a stark differentiation for takeaway food services that require something special and specific for brand identity.

Fourth, the public pressure for sustainable choices is still weak and thereby doesn't help to accelerate choice developments by the packaging industry. In my initial survey results, price, quality or convenience rated higher at times than the packaging choice. Upon further reflection, this makes perfect sense since there is more happening in the food selection than just packaging. Decisions in costs, nutrition, schedules, may determine more of our packaging needs than sustainability requirements. Despite small cadres of zero-waste movement and the plastic backlash effect, the lose-win nature of packaging vs. food-needs is just a commonly accepted consequence. Further research would be needed to understand if people are aware of the packaging problems or are aware and have limited means of confronting these choices, or to determine if and when the sustainable packaging becomes more important than other needs.

When it comes to testing my examples, there were two interesting results. First, people in workshops posed lots of questions about alternative packaging examples. This could be due to the fact that the workshops were done face-to-face and conversation is inevitable, and people are politely curious. Also, I'm not sure I can qualify their reactions as hesitations, concerns or just conversation. This is further complicated by the fact that I had an iterative testing process and as notoriety grew about my packaging testing, participants may have become more comfortable asking questions. These questions mostly revolved around concerns of hygiene, sanitation and longevity of the packaging material. This is noncomprehensive, but it does highlights some of the challenges facing eco-alternative packaging. Further research would be needed to understand consumer concerns regarding eco-alternative packaging, to measure these concerns in comparison to plastic packaging concerns, or to tabulate exposure and acceptance of eco-alternatives options.

Finally, after great consideration, I doubt that any packaging design can exist in a throw-away culture as an acceptable ethical solution. No matter what, the packaging design will contribute some ill. If the packaging is edible but not eaten, then the design contributes to food waste. If it is compostable but not composted it is wasted material. If its high-heat compostable but not within range of industrial composting it will take up space and waste resources decaying in a landfill. Across the board, throw-away packaging carries the burden of waste in comparison to reusable packaging. In short, I see no solutions to takeaway packaging that is guilt-free in a throw-away culture. 
Still, some populations and countries seem to be facing the upcoming challenges with gusto as mentioned in Chapter 1. The changes in policy like the green-dot packaging in Germany, plastic-banning in France, and the U.K. government pushing the "War on Plastics" may be just the impetus that will push packaging changes faster into our foreseeable future. Maybe the switch to eco-alternative packaging will be more viable in the coming years. Hopefully, future design contributions will further emphasize the reusable food-grade safe utility of materials (glass, etc.), or provide a novelty gateway introduction via eco-alternatives in the future that we can consider more healthy and sustainable than dangerous plastic designs. 


\section{Annex 1: Online Survey}

Online survey created by Sara Martí in October 2017. This survey was administered online via SurveyMonkey.com to 132 people in the months of October and November of 2017.

Survey Objectives:

- To understand current behaviors and perceptions regarding food packaging.

- To understand how current populations consider biodegradable, compostable and/or edible packaging materials in food packaging.

The purpose of this survey is to understand how food packaging influences consumer buying decisions. It is part of a final dissertation project for the Masters course "MA in Design for Social Impact" based at the Paris College of Art. Your responses will be kept confidential and will be used for research purposes only.

The following definitions are used throughout:

1. Biodegradable refers to the ability of materials to break down and decompose into natural elements

2. Compostable refers to the ability of materials to break down and decompose into natural elements that further enhance a composting process into producing rich soil

3. Edible refers to the ability of materials to be suitable and safe to be consumed by humans Please attempt to answer all questions and tick one answer only, unless indicated otherwise. Thank you for your participation 
1. Which of the following are important criteria for packaging material? (select all that apply)

$\bigcirc$ durability

$\bigcirc$ texture

protection

$\bigcirc$ preservation

$\bigcirc$ safety

visibility

$\bigcirc$ biodegradable

compostable

recyclable

Other (please specify

2. How do you decide which food (and corresponding packaging) to purchase? (select all that apply)

purchase the same one all the time

$\bigcirc$ go for the brand of the product

$\bigcirc$ depends on the quantity

$\bigcirc$ look at the packaging

$\bigcirc$ depends on the price

promotion that may be on offer

Other (please specify 
3. Rate the influence of the product elements according to how it influences you to buy a product?

$$
\text { Strong influence Slight influence No }
$$

influence

Brand of the product

Promotion on the product

0

0

Packaging

Quality

Price

Advertising

Convenience

Product availability
0

0

0

0

$\bigcirc$

$\bigcirc$

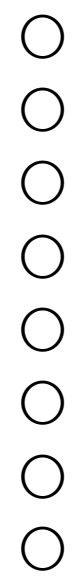

0

0

0

0

0

0

0

$\bigcirc$

4. How strongly does packaging influence your buying decision when purchasing food products?
Very strongly
Strongly
Average
No influence at

all

5. Rate the following materials according to your preferences on food packaging (1 highest to 5 lowest)

$\begin{array}{lccccc} & 1 & 2 & 3 & 4 & 5 \\ \text { Glass } & \bigcirc & \bigcirc & \bigcirc & \bigcirc & \bigcirc \\ \text { Plastic } & \bigcirc & \bigcirc & \bigcirc & \bigcirc & \bigcirc \\ \text { Metal } & \bigcirc & \bigcirc & \bigcirc & \bigcirc & \bigcirc \\ \text { Biodegradable } & \bigcirc & \bigcirc & \bigcirc & \bigcirc & \bigcirc \\ \text { Compostable } & \bigcirc & \bigcirc & \bigcirc & \bigcirc & \bigcirc\end{array}$

6. In your opinion, how important is packaging when choosing food product?
$\bigcirc$ Very important $\bigcirc$ Important
$\bigcirc$ Average
Not important

7. How important is convenience to you when choosing a food product?
$\bigcirc$ Very important
Important
$\bigcirc$ Average
Not important 
8. How often do you buy food that has packaging made of biodegradable materials?
$\bigcirc$ Frequently
Sometimes
$\bigcirc$ Never

9. How often do you buy food that has packaging made of compostable materials?
$\bigcirc$ Frequently
Sometimes
$\bigcirc$ Never

10. How often do you buy food that has packaging made of edible materials?
$\bigcirc$ Frequently
Sometimes
$\bigcirc$ Never

11. How likely are you to consider biodegradable packaging as a priority in your food purchase?
$\bigcirc$ Frequently
$\bigcirc$ Sometimes
Never

12. How likely are you to consider compostable packaging as a priority in your food purchase?
$\bigcirc$ Frequently
Sometimes
$\bigcirc$ Never

13. How likely are you to consider edible packaging as a priority in your food purchase?
$\bigcirc$ Frequently
$\bigcirc$ Sometimes
$\bigcirc$ Never

14. How many times in the last 5 years have you purchased a food product due to its biodegradable packaging materials?
$\bigcirc$ Never
$1-5$ times
5-10 times
Other

15. How many times in the last 5 years have you purchased a food product due to its compostable packaging materials?
$\bigcirc$ Never
1-5 times
5-10 times
$\bigcirc$ Other

16. How many times in the last 5 years have you purchased a food product due to its edible packaging materials?
$\bigcirc$ Never
$\bigcirc 1-5$ times
5-10 times
$\bigcirc$ Other 
17. In the next year how likely are you to purchase a food product in biodegradable packaging?
$\bigcirc$ Most likely
Probably
$\bigcirc$ Unlikely
Undecided

18. In the next year how likely are you to purchase a food product in compostable packaging?
$\bigcirc$ Most likely
Probably
$\bigcirc$ Unlikely
Undecided

19. In the next year how likely are you to purchase a food product in edible packaging?
$\bigcirc$ Most likely
$\bigcirc$ Probably
$\bigcirc$ Unlikely
$\bigcirc$ Undecided

20. How do you feel about biodegradable food packaging materials?

21. How do you feel about compostable food packaging materials?

22. How do you feel about edible food packaging materials?

23. What is your gender?
Male
Female

24. What is your age?

$\bigcirc$ younger than 15 

(15-25
26-35
36-45
46-55
56-65
$\bigcirc 66$ and above

25 . What is your current yearly income?
less than 10,000 euros
10,000-24,999 euros
25,000-49,999 euros
(50,000-79,999 euros
$\bigcirc$ over 80,000 euros 


\section{Annex 2: Workshop Interviews}

Martí, Sara. (January 2018) Workshop In-Depth Taste-Testing Interview for Paris College of Art. *A total of 10 interviews were held at Paris College of Art with two people testing at a time for a total of 5 sessions from mid-January to mid-February of 2018.

My name is Sara Marti (Smarti) and welcome to my workshop series where I test out different versions of packaging on willing participants. I'll be taking your names, writing down notes and video-recording this experience and it's all for educational purposes I won't publish the images without your information.

The workshop is broken into 3 sections. The first is just you to explore the packaging, open it, eat, sniff, taste, whatever you like. The second section is me asking a series of questions about your daily habits. The third section is particular to the package you have.

So, go ahead and start, and I'll just be right back. [leave camera running]

What is your name?

Which program are you in?

How do like Paris?

How often do you eat out?

What kind of food do you normally eat for takeout?

What is the best container experience you have had?

Worst?

What do you do with your container after you finish?

How many containers do you think you'll go through in your lifetime?

Do you know what the zero-waste movement is?

What zero-waste habits do you do every day?

What zero-waste habits do you consider difficult?

Is the package size-appropriate for a regular take-away experience? If so, how?

Does the package communicate that it will contain everything responsibly? Leakage?

Does the package have a flavor? Does the package distort the flavor of the food?

Do you think the package would contain the heat or coldness of the food inside? 
Does the package seem fresh? If so, how?

Does it seem sanitary? If so, how?

Describe how you opened and initial reaction of the package.

Describe the shape and structural flaws of the package. How did it make you feel?

Describe the material and texture of the package. How did it make you feel?

Describe how you would finish using the package. How does that make you feel?

So now I'll tell you about how the packages were made. This one is linseed, chia and agaragar (seaweed) mixed with water and put into a plate mold to dry with paper cross to support the package. It is slow-baked in a dehydrator at 110 Fahrenheit and it takes a day to mix, coat, and dry. The topping is banana water blend coating to give it a sticky finish so that the top can seal and protect the food.

Now that you have finished your meal I'd like to ask you to doodle a different version if you have ideas in mind for me to improve the model or test a new idea.

\begin{tabular}{|l|l|l|}
\hline Type & & \\
\hline Name & & \\
\hline Quotes & & \\
\hline Behavioral & & \\
\hline size & & \\
appropriate & & \\
\hline leakage & & \\
\hline flavor & & \\
\hline heat/cold & & \\
\hline freshness & & \\
\hline Visceral & & \\
\hline
\end{tabular}




\begin{tabular}{|l|l|l|}
\hline structure & & \\
\hline material & & \\
\hline texture & & \\
\hline shape & & \\
\hline Reflective & -- & - \\
\hline
\end{tabular}




\section{Annex 3: Quick Taste-Test Interviews at Carrefour Numerique ${ }^{2}$}

Martí, Sara. (January 2018) Workshop Taste-Testing Interview for Carrefour Numerique, Cite des Science et de l'Industrie For “Au Fil du Plastique" Event February 18 until March 1, 2018. Total of 42 family style (to accommodate young children) workshops with 70 participants.

My name is Sara Marti (Smarti) and thank you for volunteering for a taste-test of the edible packaging concept. I'll be taking your names, asking you questions and writing down notes to record this experience. It's all for educational purposes and I won't publish the images if you decline on the permission forms.

Taste-testing in Carrefour Numerique

1. What do you think about this packaging?

Devines la fonction de cet objet? A quoi cela sert?

Quelles matières ont permises de le créer?

A quoi cet objet te fait penser/ à quoi il ressemble?

2. Do you experience choice of packaging in takeaway?

Avez-vous l'expérience du choix de l'emballage à emporter?

3. How do you manage packaging waste?

Comment gérez-vous les déchets d'emballage?

4. What would you do with this packaging?

Dans quelle poubelle est-ce que tu jetterais cet emballage?

5. What would you change about this packaging?

Qu'est que vous changerez de cet emballage? 


\section{Annex 4: Permission Forms for Carrefour Numerique ${ }^{2}$}

Permission forms created by Sara Martí and Melissa Richards from Carrefour Numerique ${ }^{2}$ at Cité des Science et de l'Industrie in Paris, France. Form 1 is general consent form. Form 2 is authorizing parent consent for children participation in workshops.

\section{Form 1: General Consent Form}

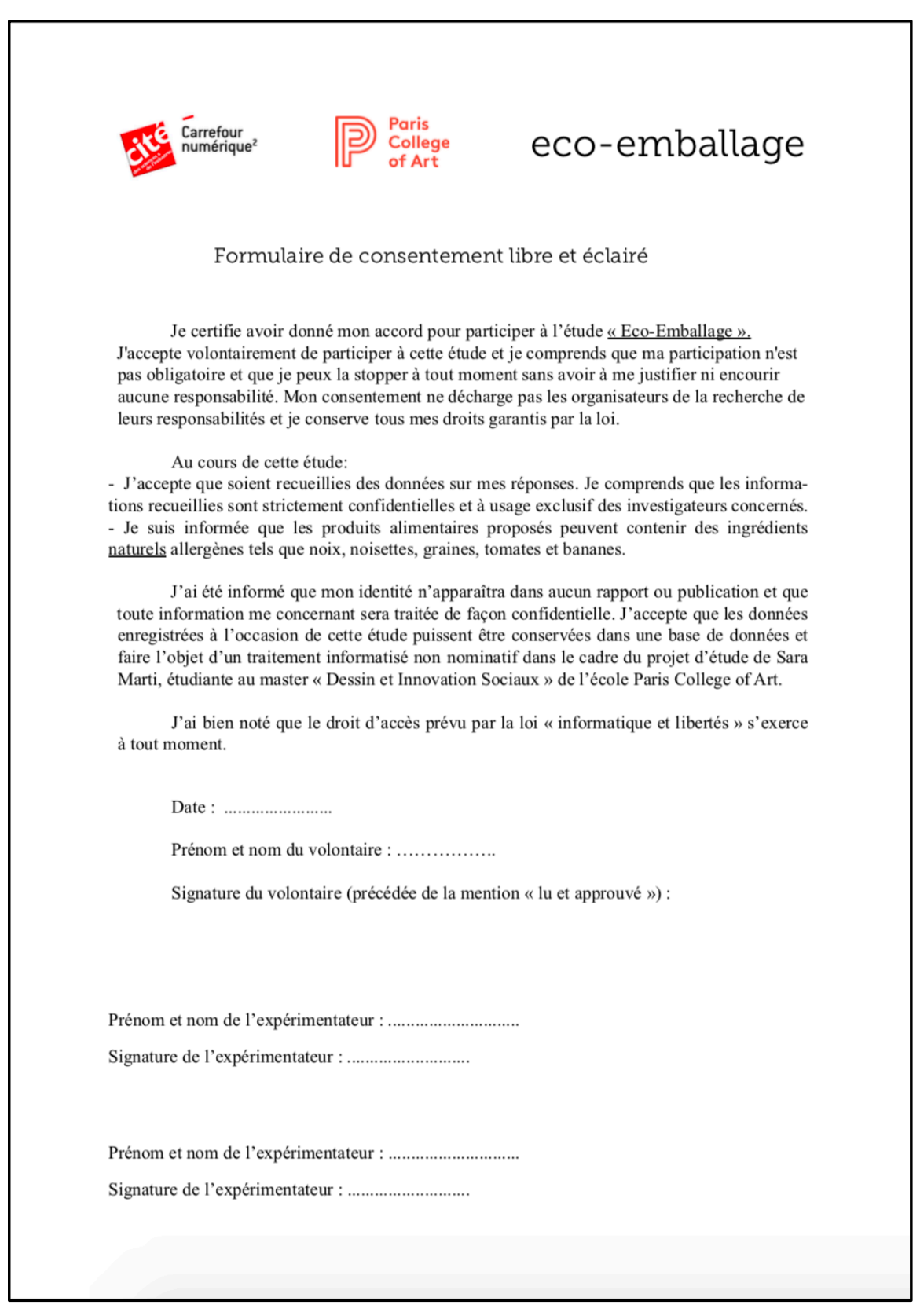

Form 2: Consent Form for a Minor 


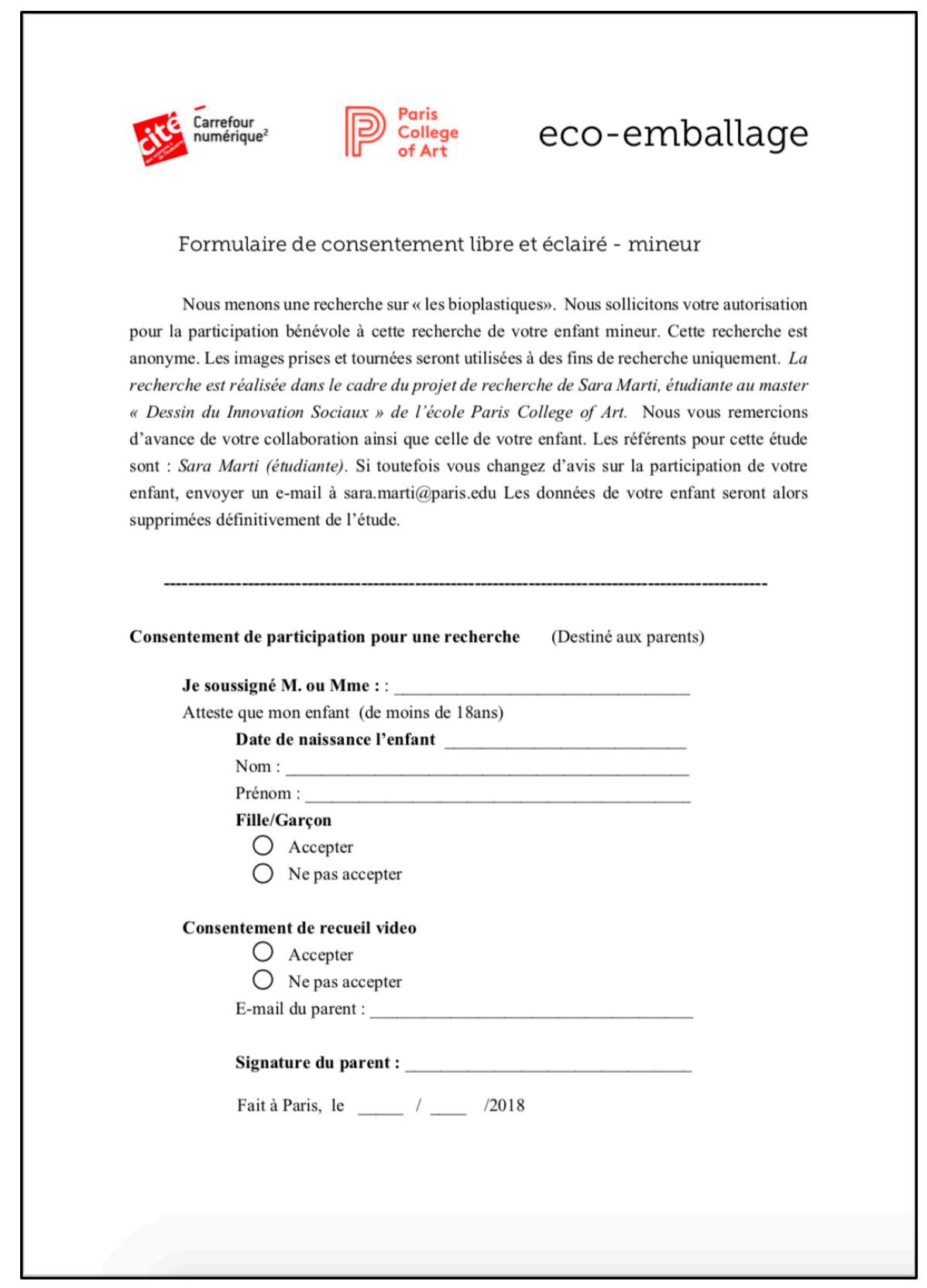




\section{Bibliography}

Albright, M. (2015, August 03). Food Packaging: Have Your Cake and Eat the Wrapper, Too.

Retrieved November 01, 2017, from

http://theplate.nationalgeographic.com/2015/07/21/

food-packaging-have-your-cake-and-eat-the-wrapper-too

Andrady, A. (2015) Plastics and Environmental Sustainability. New Jersey: John Wiley \& Sons.

A Student in Iceland May Have Just Saved The Planet (n.d.) Retrieved October 01, 2017, from http://emgn.com/entertainment/student-iceland-may-just-saved-planet/

Avena-Bustillos, R.J., Azeredo, H., Lorevice, M., Mattoso, L., McHugh, T., Moura, M., \& Otoni, C. (2017). Recent Advances on Edible Films Based on Fruits and Vegetables A Review. Comprehensive Reviews in Food Science and Food Safety, 16(5). P11511169. doi: 10.1111/1541-4337.12281

Baranovska, H. (2010 September 7) 360 Paper Bottle, Retrieved online:

http://designand.blogspot.fr

Bizzizero, J. (2017 October 19) Packaging 2.0: What's outside is just as important as what's inside. Natural Products Insider. Retrieved October 22, 2017, from https://www.naturalproductsinsider.com/articles/2017/10/packaging-20-whatsoutside-is-just-as-important-as-whats-inside.aspx

Boztas, S. (2016, October 26). Compostable and edible packaging: the companies waging war on plastic. Retrieved September 14, 2017, from https://www.theguardian.com/sustainable-business/2016/oct/26/plastics-foodpackaging-microplastics-waste-ocean-pollution-compost-snact-tipa-nestle-usda

Bryson, B. (2016). A short history of nearly everything. London: Black Swan.

Cedervall, T., Hansson, L., Lard, M., Frohm, B., \& Linse, S. (2012). Food Chain Transport of Nanoparticles Affects Behaviour and Fat Metabolism in Fish. PLoS ONE, 7(2). doi:10.1371/journal.pone.0032254

Cohen, H. (2017 March 21) Retrieved 4 February 2018 from http://www.lhi.is/en/news/ari-jonsson-product-design-student-awarded

Clarke, A. J. (2001). Tupperware: the promise of plastic in 1950s America. Washington, DC: Smithsonian Inst. Press.

Cózar, A., Sanz-Martín, M., Martí, E., González-Gordillo, J. I., Ubeda, B., Gálvez, J. Á, . . . 
Duarte, C. M. (2015). Plastic Accumulation in the Mediterranean Sea. Plos One, 10(4). doi:10.1371/journal.pone.0121762

Derkson, L., \& Gartrell, J. (1993). The Social Context of Recycling. American Sociological Review, 58(3), 434-442. Retrieved November 25, 2017, from http://www.jstor.org/stable/2095910

Edible Packaging for food by Tomorrow Machine Design Studio. (2015, September 08). Retrieved January 15, 2018, from https://www.ateriet.com/future-packagingtomorrowmachine/

Escobedo, T. (2017, May 11). 5 cool inventions that could save the planet. Retrieved February

28, 2018, from https://edition.cnn.com/2017/05/11/tech/ecosolutions-5-waystech/index.html

Evans-Brown, S. (2014, September 16). Edible Packaging? Retailers Not Quite Ready To Ditch

The Wrapper. Retrieved February 28, 2018, from

https:/www.npr.org/sections/thesalt/2014/09/16/348957715/edible-packagingretailers-not-quite-ready-to-ditch-the-wrapper

Evoware/NowJakarta! (2018 January 14) Evoware Seaweed Sachet, Retrieved online: http://nowjakarta.co.id/evoware-reducing-plastic-waste-with-edible-cups-foodwrappings-and-sachets

Evoware website (n.d.) Retrieved 28 February 2018 from http://www.evoware.id First plastic-free aisle is an example for other supermarkets to follow | Letters. (2018, February

28). Retrieved February 28, 2018, from

https://www.theguardian.com/environment/2018/feb/28/first-plastic-free-aisle-is-anexample-for-other-supermarkets-to-follow

Gendell, A. (2018 January 30) 2 New Year's resolutions for sustainable packaging in 2018.

Retrieved 4 February 2018 from http://www.packagingdigest.com/sustainablepackaging /2-new-years-resolutions-for-sustainable-packaging-in-2018-2018-01-30

Geyer, R., Jambeck, J. R., \& Law, K. L. (2017). Production, use, and fate of all plastics ever made. Science Advances, 3(7). doi:10.1126/sciadv.1700782 http://advances.sciencemag.org/content/3/7/e1700782.full 
Grozdanic, L. (2017 January 9), Avani Eco “I Am Not Plastic” Bag, Retrieved online: https://inhabitat.com/dissolvable-bioplastic-bags-from-bali-are-safe-enough-todrink/avani-eco-bags-3)

Freinkel, S. (2011). Plastic: a toxic love story. Boston: Houghton Mifflin Harcourt.

Freudenrich, C. (2007, December 14). How Plastics Work. Retrieved November 12, 2017, from https://science.howstuffworks.com/plastic1.htm

Hine, T. (1998). The total package. London: Little, Brown.

Hook, P \& Bond, C. (n.d.) A History of Packaging. Retrieved 15 January 2018 from https://ohioline.osu.edu/factsheet/cdfs-133

Hoyt, A. (2017, September 12). Why Throw Out Packaging When You Could Just Eat It? Retrieved September 12, 2017, from http://science.howstuffworks.com/environmental/green-science/edible-packaging.htm

Knight, L. (2014, May 17). A brief history of plastics, natural and synthetic. Retrieved November 12, 2017, from http:/www.bbc.com/news/magazine-27442625

Koester, E. (2015) Green Entrepreneur Handbook: the guide to building and growing a clean and green business. Boca Raton, CRC Press.

Kumala, K. (2017, May 24). From Waste to Worth: The Invention of Cassava Bag TEDxUSMNibongTebal Retrieved February 28, 2018, from https://www.youtube.com/watch?v=Q0j325WfvCA

Lapidos, J. (2007, June 27). Do plastic bags really take 500 years to break down in a landfill? Retrieved November 25, 2017, from http://www.slate.com/articles/news_and_politics/ explainer/2007/06/will_my_plastic_bag_still_be_here_in_2507.html

Laskow, S. (2014, October 10). How the Plastic Bag Became So Popular. Retrieved November

15, 2017, fromhttps://www.theatlantic.com/technology/archive/2014/10/how-theplastic-bag-became-so-popular/381065/

Law, K. L. (2016). Plastics in the marine environment. Annual Review of Marine Sciences, 9 ,

205-229. doi:10.1146/annurev-marine-010816-060409

Leonard, A., \& Conrad, A. (2011). The story of stuff: How our obsession with stuff is trashing

the planet, our communities, and our health--and a vision for change. New York: Free Press.

Loliware/Amazon.com. (2010 August 16) Loliware Cups, Retrieved online: 
https://www.nutraingredients-usa.com/Article/2016/08/17/Shark-Tank-winner-

Loliware-DSM-cooperate-to-make-edible-vitamin-cups

Linnenkoper, K. (2017, November 21). Debate: is the future of packaging oxo-biodegradable.

Retrieved November 23, 2017, from

https://www.recyclinginternational.com/recycling-news/10937/plastic-and-

rubber/global/debate-future-packaging-oxo-biodegradable

Marsh, K. and Bugusu, B. (2007). Food packaging — roles, materials, and environmental issues.

Journal of Food Science 72, (3), 39-55.

Matos, G., \& Wagner, L. (1998). Consumption of Materials in the United States, 1900-1995

(Annual Review of Energy and The Environment, pp. 1-9, Rep.).

Milkmen return to London as millennials bid to cut plastic waste. (2018, February 25).

Retrieved

February 28, 2018, from https://www.standard.co.uk/news/london/milkmen-are-

returning-to-london-as-millennials-order-glass-milk-bottles-in-a-bid-to-slash-plastica3774646.html

Meikle, J. L. (1995). American plastic: a cultural history. New Brunswick, NJ: Rutgers University Press.

Meeker, J. D., Sathyanarayana, S., \& Swan, S. H. (2009). Phthalates and other additives in plastics: human exposure and associated health outcomes. Philosophical Transactions of the Royal Society B: Biological Sciences, 364(1526), 2097-2113.

doi:10.1098/rstb.2008.0268

Marsh, K. and Bugusu, B. (2007). Food packaging—roles, materials, and environmental issues.

Journal of Food Science 72, (3), 39-55.

Morby, A. (2016 March 20) Ari Jónsson Red Algae Bottle, Retrieved online:

https://www.dezeen.com/2016/03/20/ari-jonsson-algae-biodegradable-water-bottlesiceland-academy-arts-student-designmarch-2016/

Nicholson, J., \& Leighton, G. (1942, June). Plastics Come of Age. Harper's Magazine, 185, 300-308. doi:http://archive.org/details/harpersmagazine185junalde

North, E. J., \& Halden, R. U. (2013). Plastics and Environmental Health: The Road Ahead. Retrieved October 22, 2017, from https://www.ncbi.nlm.nih.gov/pmc/articles/PMC3791860/

OECD. (1998, May 15) EXTENDED PRODUCER RESPONSIBILITY PHASE 2 CASE 
STUDY ON THE GERMAN PACKAGING ORDINANCE. Retrieved February 2, 2018, from http://www.oecd.org/officialdocuments/publicdisplaydocumentpdf/?doc language $=$ en $\&$ cote $=$ env $/$ epoc $/ p p c(97) 21 /$ rev2

O'Sullivan, K. (2018, January 26). Plastic packaging: Exactly how green are our supermarkets?

Retrieved March 07, 2018, from

https://www.irishtimes.com/news/environment/plastic-packaging-exactly-how-greenare-our-supermarkets-1.3369793

Palmisano, A. C., \& Pettigrew, C. A. (1992, October). Biodegradability of plastics.

BioScience, 42(9), 680-685.

Paper-Bottle website (n.d.) Retrieved 28 February 2018 from https://paperwaterbottle.com Parker, L. (2017, July 19). A Whopping 91\% of Plastic Isn't Recycled. Retrieved October 15, 2017, from http://news.nationalgeographic.com/2017/07/plastic-produced-recycling -waste-ocean-trash-debris-environment/

Pecci, A. (2014, August 7). Unpackaged goods. Retrieved November 12, 2017, from http://www.nhbr.com/August-8-2014/Unpackaged-goods/

Pecci, A. (2014). Product takes a giant step toward edible packaging. New Hampshire Business Review, 35(16), 1-10.

Peters, A. (2017, October 06). Instead Of Throwing Out This Plastic Wrapper, You Eat It. Retrieved October 12, 2017, from https://www.fastcompany.com/40477587/insteadof-throwing-out-this-plastic-wrapper-you-eat-it

Raphael, R. (2018, February 13). Queen Elizabeth bans plastic at Buckingham Palace.

Retrieved

February 28, 2018, from https://www.fastcompany.com/40530408/queen-elizabethbans-plastic-at-buckingham-palace

Royte, E. (2006 August) Corn Plastic to the Rescue. Smithsonian Magazine. Retreived 28 February 2018 from https://www.smithsonianmag.com/science-nature/corn-plasticto-the-rescue-126404720/

Rhodes, M. (2013, October). Where Design Is Going Next. Fast Company, (179), 142-151. Schaider, L. A., Balan, S. A., Blum, A., Andrews, D. Q., Strynar, M. J., Dickinson, M. E., 
Peaslee, G. F. (2017). Fluorinated Compounds in U.S. Fast Food Packaging. Environmental Science \& Technology Letters, 4(3), 105-111. doi:10.1021/acs.estlett.6b00435

Schiller, B. (2018, January 26). These Bold Ideas Aim To Make Plastic Waste A Thing Of The

Past. Retrieved January 28, 2018, from

https://www.fastcompany.com/40521263/these-bold-ideas-aim-to-make-plasticwaste-a-thing-of-the-past

Smithers, R. (2018 January 28) An eco-friendly cuppa? Now teabags are set to go plasticfree.

Retrieved 4 February 2018 from

https://www.theguardian.com/environment/2018/jan/28/teabags-plastic-free-co-opeco-friendly

Stonyfield and Wikipearl, Inc. (2014 September 16) Wikipearl, Retrieved online: https://www.npr.org/sections/thesalt/2014/09/16/348957715/edible-packagingretailers-not-quite-ready-to-ditch-the-wrapper

Terry, B. (2012) Plastic Free: How I Kicked the Plastic Habit and How You Can Too. New York: Skyhorse Publishing.

The History and Future of Plastics. (2016, December 20). Retrieved November 12, 2017 , from https://www.chemheritage.org/the-history-and-future-of-plastics

The New Plastics Economy: Rethinking The Future of Plastics (Rep.). (2016, March 15).

Retrieved from

https://www.ellenmacarthurfoundation.org/assets/downloads/EllenMacArthurFoundat ion_TheNewPlasticsEconomy 15-3-16.pdf

The truth about recycling. (2007, June 09). Retrieved November 24, 2017, from http://www.economist.com/node/9249262

Thompson, S. (2018 January 29) Are biologically based plastics a realistic replacement for petrochemical plastics? Retrieved 4 February 2018 from https://www.irishtimes.com/news/science/are-biologically-based-plastics-a-realisticreplacement-for-petrochemical-plastics-1.3372186

Thompson, R. C., Swan, S. H., Moore, C. J., \& Saal, F. S. (2009, July 27). Our plastic age. Retrieved November 24, 2017, from http://rstb.royalsocietypublishing.org/content/364/1526/1973

Tibbetts, J. H. (2015, August). Plastic on the Half Shell. BioScience, 65(8), 836-836. 
Tonnes of rubbish is being cleared from Mount Everest - BBC Newsbeat. (2017, March 30). Retrieved February 01, 2018, from

http://www.bbc.co.uk/newsbeat/article/39442821/tonnes-of-rubbish-is-being-clearedfrom-mount-everest

TomorrowMachine (2015 March 25) Oil encased in sugar dome packaging, Retrieved online: https://design-milk.com/look-creative-packaging/

Use of plastic straws scrapped at Scottish parliament (2018 February 2) Retrieved 4 February 2018 from http://www.bbc.com/news/uk-scotland-scotland-politics-42908072

Wildermuth, S. (2016, January 19). Edible Food Packaging [Web log post]. Retrieved September

20, 2017, from https://blogs.chapman.edu/scst/2016/01/19/edible-food-packaging/ Wallace, M. (2016). Risk Criticism. S.1.: University of Michigan Press.

Welcome | Biota Spring Water. (n.d.). Retrieved January 15, 2018, from http://www.biotaspringwater.com/

World Plastics Production 1950-2015 (pp. 1-8, Rep.). (n.d.). Retrieved November 24, 2017, from

https:/committee.iso.org/files/live/sites/tc61/files/The\%20Plastic\%20Industry\%20Be rlin\%20Aug\%202016\%20-\%20Copy.pdf

Yuniar, R. W. (2018, February 11). Has the West learned its lesson from China's plastic ban? Retrieved February 28, 2018, from http:/www.scmp.com/weekasia/politics/article/2132771/journey-waste-has-west-learned-its-lesson-chinasplastic-ban 